\title{
Genome-Wide Association Analysis of Young Onset Stroke Identifies a Locus on Chromosome 10q25 Near HABP2
}

Yu-Ching Cheng, PhD; Tara M. Stanne, PhD; Anne-Katrin Giese, MD; Weang Kee Ho, PhD; Matthew Traylor, PhD; Philippe Amouyel, MD, PhD; Elizabeth G. Holliday, PhD; Rainer Malik, PhD; Huichun Xu, MD, PhD; Steven J. Kittner, MD; John W. Cole, MD; Jeffrey R. O'Connell, PhD; John Danesh, DPhil, FRCP; Asif Rasheed, MBBS; Wei Zhao, MSc;

Stefan Engelter, MD; Caspar Grond-Ginsbach, PhD; Yoichiro Kamatani, MD, PhD; Mark Lathrop, PhD; Didier Leys, MD, PhD; Vincent Thijs, MD, PhD;

Tiina M. Metso, MD, PhD; Turgut Tatlisumak, MD, PhD; Alessandro Pezzini, MD; Eugenio A. Parati, MD; Bo Norrving, MD, PhD; Steve Bevan, PhD;

Peter M. Rothwell, MD, PhD, FRCP; Cathie Sudlow, DPhil, FRCP;

Agnieszka Slowik, MD, PhD; Arne Lindgren, MD, PhD; Matthew R. Walters, MD;

WTCCC-2 Consortium; Jim Jannes, PhD; Jess Shen, MSc; David Crosslin, PhD; Kimberly Doheny, PhD; Cathy C. Laurie, PhD; Sandip M. Kanse, PhD; Joshua C. Bis, PhD;

Myriam Fornage, PhD; Thomas H. Mosley, PhD; Jemma C. Hopewell, PhD;

Konstantin Strauch, PhD; Martina Müller-Nurasyid, MD, PhD; Christian Gieger, PhD;

Melanie Waldenberger, PhD, MPH; Annette Peters, PhD; Christine Meisinger, MD;

M. Arfan Ikram, MD, PhD; W.T. Longstreth Jr, MD, MPH; James F. Meschia, MD;

Sudha Seshadri, MD; Pankaj Sharma, PhD, MD; Bradford Worrall, MD, MSc;

Christina Jern, MD, PhD; Christopher Levi, MBBS; Martin Dichgans, MD;

Giorgio B. Boncoraglio, MD; Hugh S. Markus, MD; Stephanie Debette, MD, PhD;

Arndt Rolfs, MD; Danish Saleheen, MBBS, PhD; Braxton D. Mitchell, PhD

Received August 27, 2015; final revision received November 6, 2015; accepted November 18, 2015

From the Veterans Affairs Maryland Health Care System, Baltimore, MD (Y.-C.C., S.J.K., J.W.C., B.D.M.); University of Maryland School of Medicine, Baltimore (Y.-C.C., H.X., S.J.K., J.W.C., J.R.O., B.D.M.); The University of Gothenburg, Gothenburg, Sweden (T.M.S., C.J.); University of Rostock, Rostock, Germany (A.-K.G., A. Rolfs); University of Nottingham Malaysia Campus, Selangor Darul Ehsa, Malaysia (W.K.H.); University of Cambridge, Cambridge, UK (M.T., J.D., S.B., H.S.M., S.D., D.S.); Institut Pasteur de Lille, F-59000 Lille, France (P.A.); University of Newcastle, Australia (E.G.H.); Ludwig-Maximilians-Universität, Munich, Germany (R.M., K.S., M.D.); Wellcome Trust Sanger Institute, Cambridge, UK (J.D.); Center for Non-Communicable Diseases, Karachi, Pakistan (A. Rasheed, D.S.); University of Pennsylvania (W.Z., D.S.); Basel University Hospital, Switzerland (S.E.); Heidelberg University Hospital, Germany (C.G.-G.); Centre d'Étude du Polymorphisme Humain, Paris, France (Y.K.); RIKEN Center for Integrative Medical Sciences, Yokohama, Japan (Y.K.); National Genotyping Center, Evry, France (M.L.); Genome Quebec, McGill University, Montreal, Canada (M.L.); Lille University Hospital, France (D.L., S.D.); KU Leuven - University of Leuven, Leuven, Belgium (V.T.); Vesalius Research Center, VIB, Leuven, Belgium (V.T.); University Hospitals Leuven, Leuven, Belgium (V.T.); Helsinki University Central Hospital, Helsinki, Finland (T.M.M., T.T.); Università degli Studi di Brescia, Brescia, Italy (A. Pezzini); Fondazione IRCCS Istituto Neurologico Carlo Besta, Milan, Italy (E.A.P., G.B.B.); University of Lund, Sweden (B.N.); University of Oxford, John Radcliffe Hospital (P.M.R.); University of Edinburgh, Edinburgh, UK (C.S.); Jagiellonian University Medical College, Krakow, Poland (A.S.); Lund University, Lund, Sweden (A.L.); Skåne University Hospital, Lund, Sweden (A.L.); University of Glasgow, Glasgow, UK (M.R.W.); University of Adelaide, Australia (J.J.); Mount Sinai Hospital, Toronto, Ontario (J.S.); University of Washington, Seattle, Washington (D.C., C.C.L., J.C.B., W.T.L.); Johns Hopkins University School of Medicine, Baltimore, MD (K.D.); University of Oslo, Oslo, Norway (S.M.K.); The University of Texas Health Science Center at Houston (M.F.); University of Mississippi Medical Center, Jackson, MS (T.H.M.); University of Oxford, Oxford, UK (J.C.H.); Helmholtz Zentrum München - German Research Center for Environmental Health, Neuherberg, Germany (K.S., M.M.-N., C.G., M.W., A. Peters, C.M.); University Hospital Grosshadern, Munich, Germany (M.M.-N.); DZHK (German Centre for Cardiovascular Disease), partner site Munich, Germany (M.M.-N., A. Peters); Erasmus University Medical Center Rotterdam, Netherlands (M.A.I.); Mayo Clinic, FL (J.F.M.); Boston University School of Medicine, Boston, MA (S.S.); Royal Holloway, University of London, UK (P.S.); University of Virginia, Charlottesville, VA (B.W.); John Hunter Hospital, Newcastle, Australia (C.L.); and University Hospital of Bordeaux, France (S.D.).

Guest Editor for this article was Christopher L.H. Chen, FRCP.

The online-only Data Supplement is available with this article at http://stroke.ahajournals.org/lookup/suppl/doi:10.1161/STROKEAHA. 115.011328/-/DC1.

Correspondence to Braxton D. Mitchell, PhD, University of Maryland, School of Medicine, 685 W Baltimore St, MSTF 302, Baltimore, MD 21201. E-mail bmitchel@medicine.umaryland.edu

(c) 2016 American Heart Association, Inc. 
Background and Purpose - Although a genetic contribution to ischemic stroke is well recognized, only a handful of stroke loci have been identified by large-scale genetic association studies to date. Hypothesizing that genetic effects might be stronger for early- versus late-onset stroke, we conducted a 2-stage meta-analysis of genome-wide association studies, focusing on stroke cases with an age of onset $<60$ years.

Methods-The discovery stage of our genome-wide association studies included 4505 cases and 21968 controls of European, South-Asian, and African ancestry, drawn from 6 studies. In Stage 2, we selected the lead genetic variants at loci with association $P<5 \times 10^{-6}$ and performed in silico association analyses in an independent sample of $\leq 1003$ cases and 7745 controls.

Results-One stroke susceptibility locus at 10q25 reached genome-wide significance in the combined analysis of all samples from the discovery and follow-up stages (rs11196288; odds ratio $=1.41 ; P=9.5 \times 10^{-9}$ ). The associated locus is in an intergenic region between TCF7L2 and HABP2. In a further analysis in an independent sample, we found that 2 single nucleotide polymorphisms in high linkage disequilibrium with rs11196288 were significantly associated with total plasma factor VII-activating protease levels, a product of $H A B P 2$.

Conclusions-HABP2, which encodes an extracellular serine protease involved in coagulation, fibrinolysis, and inflammatory pathways, may be a genetic susceptibility locus for early-onset stroke. (Stroke. 2016;47:00-00. DOI: 10.1161/STROKEAHA.115.011328.)

Key Words: factor VII $\boldsymbol{\square}$ genetics $\boldsymbol{\square}$ genome-wide analysis $\boldsymbol{\square}$ ischemic stroke $\boldsymbol{\square}$ stroke

$\mathrm{S}_{\mathrm{s}}^{\mathrm{u}}$ troke is the fourth leading cause of death in the United States and a major cause of long-term disability among adults. ${ }^{1}$ Ischemic stroke, the predominant type of stroke, has a multifactorial pathogenesis, with heritability estimated at $37 \%-38 \% .^{2,3}$ One approach to gain insights into the molecular basis underlying stroke susceptibility is to identify stroke susceptibility genes and then assess the functions of these genes. A handful of stroke susceptibility loci have recently been identified. ${ }^{4,5}$ Additional stroke susceptibility loci can perhaps be identified by studying special high risk populations or focusing on specific subtypes of stroke.

We focus in this study on identifying susceptibility loci associated with early-onset stroke, based on the premise that variants associated with younger onset stroke might have higher penetrance and effect sizes than those associated with older onset stroke. Disease-associated variants have been associated with early-onset forms of numerous other complex diseases, including breast cancer, diabetes mellitus, and heart disease. Although a minority of stroke cases occur at young age, the best available evidence suggests that stroke at younger ages has a stronger genetic basis than stroke occurring at older ages. ${ }^{4}$

To identify loci associated with early-onset stroke, we conducted a 2-stage genome-wide association study (GWAS), in which we meta-analyzed 6 individual studies in the Discovery Stage and then followed up suggestively associated loci in independent samples. In a combined analysis of the discovery and follow-up stages, we detected significant evidence for association to a locus on chromosome 10q25 that met genome-wide significance thresholds. Further analyses of this locus suggest a possible link to hyaluronan-binding protein 2 (HABP2), which encodes Factor VII-activating protease.

\section{Methods}

\section{Genome-Wide Association Meta-Analysis}

The discovery stage for the GWAS meta-analysis included 4505 earlyonset ischemic stroke cases and 21968 controls from 6 case-control studies (Table). Our analysis included only early-onset ischemic stroke cases, defined as stroke age of onset $<60$ years using studyspecific diagnostic criteria. Two of the discovery stage studies by design included only young onset cases (Genetics of Early-Onset Stroke [GEOS] and Stroke in Young Fabry Patients [SIFAP]). Four of the discovery studies included individuals of European ancestry only, one included individuals of South-Asian ancestry only, and one included individuals of both European ancestry and African Americans. Three of the studies by design included previously genotyped controls selected from the same geographic region as the cases and genotyped on the same single nucleotide polymorphism (SNP) array.

The follow-up stage included a total of 1003 independent, early-onset cases and 7745 controls from 3 independent case-control studies of European ancestry populations. Study-specific subject inclusion/exclusion criteria are provided in the online-only Data Supplement,-and-study characteristics and sample sizes are summarized in Table; Tables I and II in the online-only Data Supplement.

All studies were genotyped on Illumina SNP arrays (San Diego, CA). Following data cleaning, principal component analyses were performed to identify population outliers and to determine population substructure for adjustment in the association analyses. Quality control filters for samples and SNPs were applied within each study before imputation (Tables III and IV in the online-only Data Supplement). Imputation was performed in the discovery stage samples based on either the 1000 Genomes Phase 1 interim reference panel or the Phase 1 integrated reference panel using IMPUTE2 software (Table III in the online-only Data Supplement). ${ }^{6}$ Postimputation filters further excluded SNPs from association analyses having minor allele frequency (MAF) $<1 \%$ or imputation quality score $($ INFO) $<0.3$. In the follow-up stage studies, all studies were imputed using 1000 Genomes Phase 1 integrated reference panel before association testing.

For the 3 studies that by design included previously genotyped controls (Risk Assessment of Cerebrovascular Events Study [RACE] I, SIFAP, and Wellcome Trust Case-Control Consortium 2 [WTCCC2]-UK), additional quality control steps, such as removing SNPs with evidence for differential missingness, were performed to ensure comparability of genotyping performance between cases and controls. Q-Q plots for all studies revealed no evidence for genomic inflation (lambdas ranging from 1.00 to 1.06 ) and the meta-analysis was further genomic control-corrected.

Detailed information about the genotyping platforms, genotype cleaning procedures, imputation process, and association analysis modeling is described in the online-only Data Supplement and Tables III and IV in the online-only Data Supplement. 
Table. Characteristics of Participating Studies

\begin{tabular}{|c|c|c|c|c|c|c|c|c|c|}
\hline \multirow[b]{2}{*}{ Study } & \multicolumn{3}{|c|}{ Cases } & \multicolumn{3}{|c|}{ Controls } & \multirow[b]{2}{*}{ External Control } & \multirow[b]{2}{*}{ Ancestry } & \multirow[b]{2}{*}{ Country } \\
\hline & Subjects, $\mathrm{n}$ & Age, mean (SD) & Male, n (\%) & Subjects, n & Age, mean (SD) & Male, n (\%) & & & \\
\hline \multicolumn{10}{|c|}{ Stage 1: discovery stage } \\
\hline CADISP & 555 & $43.7(9.9)$ & $339(61.1)$ & 9259 & $\mathrm{~N} / \mathrm{A}$ & $\mathrm{N} / \mathrm{A}$ & No & EA & $\begin{array}{c}\text { Belgium, } \\
\text { France, } \\
\text { Germany, Italy, } \\
\text { Switzerland, and } \\
\text { Finland }\end{array}$ \\
\hline GEOS EA & 448 & $41.0(7.0)$ & $275(61.4)$ & 498 & $39.5(6.7)$ & $282(56.6)$ & No & EA & USA \\
\hline GEOS AA & 381 & $41.9(6.8)$ & $207(54.3)$ & 352 & $40.0(6.8)$ & $196(55.7)$ & No & AA & USA \\
\hline MILANO & 201 & $45.0(10.4)$ & $120(60.9)$ & 407 & $50.8(8.1)$ & $357(87.8)$ & No & EA & Italy \\
\hline RACE 1 & 1218 & $50.1(9.9)$ & $638(52.4)$ & 1158 & $51.9(7.9)$ & $613(53)$ & PROMIS & South Asian & Pakistan \\
\hline RACE 2 & 339 & $50.2(9.2)$ & $272(80.4)$ & 3295 & $60.9(13.2)$ & $1838(55.8)$ & PROMIS & South Asian & Pakistan \\
\hline SIFAP & 981 & $41.7(7.4)$ & $599(61.1)$ & 1824 & $55.2(11.6)$ & $899(49.3)$ & KORA & EA & Germany \\
\hline WTCCC2-UK & 382 & $51.9(7.3)$ & $228(59.7)$ & 5175 & 52 & 2611 (50.5) & $\begin{array}{l}\text { British Birth Cohort } \\
\text { and UK Blood } \\
\text { Service Control }\end{array}$ & EA & UK \\
\hline Total & 4505 & & & 21968 & & & & & \\
\hline \multicolumn{10}{|c|}{ Stage 2: Follow-up stage } \\
\hline ASGC & 227 & $52.3(8.7)$ & $151(66.5)$ & 1244 & $66.3(7.5)$ & $625(50.2)$ & No & EA & Australia \\
\hline $\begin{array}{l}\text { WTCCC2- } \\
\text { Munich }\end{array}$ & 275 & $48.8(8.5)$ & $188(68.4)$ & 797 & $62.7(10.9)$ & $410(51.4)$ & KORA & EA & Germany \\
\hline Immunochip & 501 & $48.7-53.4$ & $58 \%-73 \%$ & 5704 & $\mathrm{~N} / \mathrm{A}$ & $27 \%-50 \%$ & $\begin{array}{c}\text { No } \\
\text { American } \\
\text { Heart } \\
\text { Association }\end{array}$ & $\begin{array}{l}\text { EA } \\
\text { rican } \\
\text { ike } \\
\text { ciation. }\end{array}$ & $\begin{array}{c}\text { Belgium, } \\
\text { Germany, } \\
\text { Poland, Sweden, } \\
\text { and UK }\end{array}$ \\
\hline
\end{tabular}

AA indicates African ancestry; ASGC, Australian Stroke Genetics Collaborative; CADISP, Cervical Artery Dissection and Ischemic Stroke Patients; EA, European ancestry; GEOS, Genetics of Early-Onset Stroke; KORA, Cooperative Health Research in the Region of Augsburg [Germany]) study; MILANO, Besta Stroke Study; RACE, Risk Assessment of Cerebrovascular Events Study; SIFAP, Stroke in Young Fabry Patients; and WTCCC2, Wellcome Trust Case-Control Consortium 2.

GWAS analysis was performed within each study using a logistic regression model with case/control status as the dependent variable and SNP allelic dosage as the independent variable to test for a multiplicative effect of the SNP on risk of ischemic stroke. The study-specific effect of each SNP, expressed as the ln-transformed odds ratio (OR) or $\beta$, was obtained after adjusting for the effect of population structure and/or additional study-specific variables before meta-analysis.

To account for the multiethnic composition of studies, we performed a transethnic GWAS meta-analysis that combined association summary statistics from European, South-Asian, and African ethnic groups ( $\mathrm{n}=4505$ cases and 21968 controls from all studies). The follow-up stage ( 3 studies, $\mathrm{n}=1003$ cases and 7745 controls) consisted of European Caucasians only. Ethnic-specific $\beta$ estimates (obtained by meta-analyzing studies of the same ethnicity) were meta-analyzed assuming a random effect model to allow for heterogeneity between different ethnic groups. Post analysis, we excluded SNPs with $\mathrm{MAF}<1 \%$ and INFO $<0.3$. We additionally excluded SNPs with high between-study heterogeneity $\left(I^{2}>50 \%\right)$ and SNPs present in only 1 ethnic group.

All meta-analyses were performed using the GWAMA software and repeated using the fixed-effect model as well as Han and Eskin's random effects model (implemented with METASOFT software) to evaluate the consistency of associations. Metaanalyses were performed by 2 independent analysts, and the results were consistent.

SNPs with $P<5 \times 10^{-6}$ in the discovery stage and having high linkage disequilibrium (LD) partners that also showed evidence for association were assessed for association in the follow-up stage via in silico look-ups. A joint analysis of the combined discovery and follow-up studies was performed by meta-analyzing the study-specific estimates from all studies to obtain joint ORs and $P$ values under fixed effect model. We considered a $P$ value $<5 \times 10^{-8}$ from the joint analysis as our threshold for genome-wide statistical significance.

We also performed an European-only GWAS meta-analysis (discovery stage: $n=2567$ cases and 17163 controls from 5 studies) in which study-specific $\beta$ estimates were meta-analyzed using the inverse variance-weighted approach assuming a fixed-effect model. SNPs absent in $>2$ European studies (European-only metaanalysis) were excluded from the analysis.

We estimated that the combined sample provided $80 \%$ power to detect an odds ratio of 1.36 in the transethnic meta-analysis at $5 \%$ MAF assuming a significance level $(\alpha)$ of $5 \times 10^{-8}$. The minimal detectable odds ratio at $80 \%$ power in the European-only meta-analysis was 1.48. Power calculations were obtained using the QUANTO software.

\section{Extension to Older Onset Stroke}

We tested whether SNPs associated with young onset stroke were also associated with stroke in older populations through in silico look-ups in the METASTROKE consortium, ${ }^{7}$ a consortium comprising 15 studies of predominantly older stroke cases. METASTROKE studies already included in either the discovery or follow-up stage of the early-onset stroke GWAS were excluded from this analysis. Study-specific GWAS results obtained from METASTROKE were provided to Y.-C. Cheng for meta-analysis. Basic study design features and cohort characteristics of the METASTROKE studies have been published previously ${ }^{7}$ and are summarized in the online-only Data Supplement and Table V in the online-only Data Supplement. 


\section{Association of SNPs at 10q25 With Factor VII-Activating Protease Protein Levels}

A single locus on chromosome 10q25 near $H A B P 2$, the gene encoding factor VII-activating protease (FSAP), met genome-wide statistical significance in the joint meta-analysis. Because we considered $H A B P 2$ to be a strong biological candidate gene for ischemic stroke, we tested for association of the index SNPs at the associated locus with variation in plasma FSAP levels, which were measured in relatively healthy participants of the Sahlgrenska Academy Study on Ischemic Stroke (SAHLSIS ${ }^{8}$; see online-only Data Supplement). FSAP levels, measured by an FSAP-specific ELISA as previously described, ${ }^{9}$ were logarithmically transformed before analysis. Analyses were conducted in normolipidemic control subjects only $(n=125)$ because FSAP antigen and activity levels are increased in both ischemic stroke and hyperlipidemia. ${ }^{9}$

The statistical significance level was set at 0.05 , and $P$ values were 2-tailed. Statistical tests were performed using the SPSS Statistics software program.

\section{Results}

\section{Genome-Wide SNP Association With Early-Onset Ischemic Stroke}

The transethnic meta-analysis included 13439215 SNPs having MAF $>1 \%$ in at least 2 ethnic groups. Approximately $57 \%, 35 \%$, and $8 \%$ of the cases were from European, SouthAsian, and African ancestry, respectively (Table; Table I in the online-only Data Supplement). The mean age of stroke cases ranged between 41 and 52 years. There was evidence for genomic deflation $(\lambda=0.90$; Figure IB in the online-only Data Supplement) under the random effect model, but no evidence of genomic inflation or deflation under the fixed effect model $(\lambda=1.007)$. The strongest association was with a cluster of 12 SNPs $\left(P\right.$ values $\left.<5 \times 10^{-6}\right)$ spanning a $22 \mathrm{~kb}$ region $(\mathrm{chr} 10$ : 115042323-115064197bp; Figure 1B; Table VI in the onlineonly Data Supplement). The associated cluster fell within an intergenic region between TCF7L2 and HABP2 on chromosome 10q25.3 as shown in Figure 2 (lead SNP rs11196288;
$\mathrm{OR}=1.39, \quad P=1.24 \times 10^{-7}$, effect allele $=\mathrm{G}$, random effect model). Results of the leading SNP associations for the transethnic analysis remained similar when analyzed using the Han and Eskin's Random Effects model (rs11196288; OR=1.40, $P=1.25 \times 10^{-7}$ ) and fixed effect model (rs11196288; OR=1.39, $\left.P=1.24 \times 10^{-7}\right)$.

The 10q25.3 locus was the only locus with $P<5 \times 10^{-6}$ and was taken forward for follow-up analysis. The index SNP (rs11196288) was not genotyped in the WTCCC Immunochip study. In meta-analysis of the 2 remaining follow-up studies ( $n=502$ cases and 2041 controls), this SNP showed significant evidence for significance $(\mathrm{OR}=1.83, P$ value $=0.03)$. In the combined analysis of both discovery and follow-up studies, the 10q25.3 locus was genome-wide significant with minimal heterogeneity between studies (rs11196288: between-study heterogeneity $I^{2}=1.6 \%, P=0.42 ; \mathrm{OR}=1.41, P=9.5 \times 10^{-9}$ under the fixed effect model and $P=1.5 \times 10^{-8}$ under the random effect model; Table VII in the online-only Data Supplement). The direction of effect for the lead SNP, rs11196288, was consistent in 9 out of the 10 studies (Figure 3). Notably, the study with the inconsistent direction of effect (Besta Stroke Study [MILANO]; OR=0.93, 95\% confidence interval $[\mathrm{CI}]=0.39$ $2.21 ; P=0.86$ ) also had the lowest imputation quality score for this SNP (INFO=0.67), whereas the other 9 studies had excellent imputation quality (INFO ranging between 0.96 and $0.99)$.

The European ancestry genome wide association analysis included 2567 casešnandar17163ricontrols from 5 studies in the discovery stage (Cervical Artery Dissection and Ischemic Stroke Patients [CADISP], GEOS European ancestry, MILANO, SIFAP, and WTCCC2-UK) and was based on a total of 10537953 SNPs with MAF $>1 \%$ in the study population. Following meta-analysis and after excluding a single isolated SNP showing marginal evidence for association, a total of 21 SNPs from 4 loci showed suggestive associations with $P$
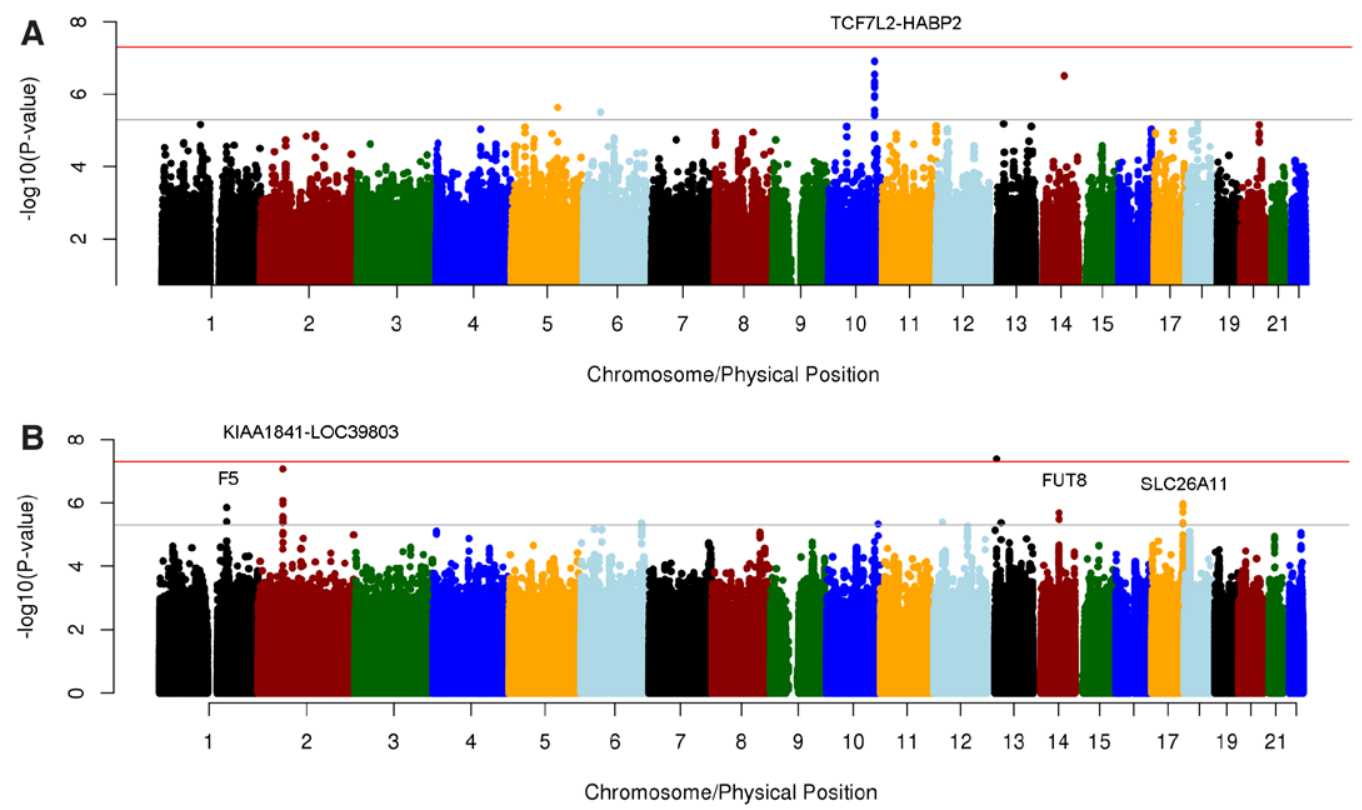

Figure 1. Genome-wide association results of early-onset ischemic stroke based on transethnic meta-analysis (A) and European-only meta-analysis (B). Red line: $P=5 \times 10^{-8}$; grey line: $P=5 \times 10^{-6}$. 


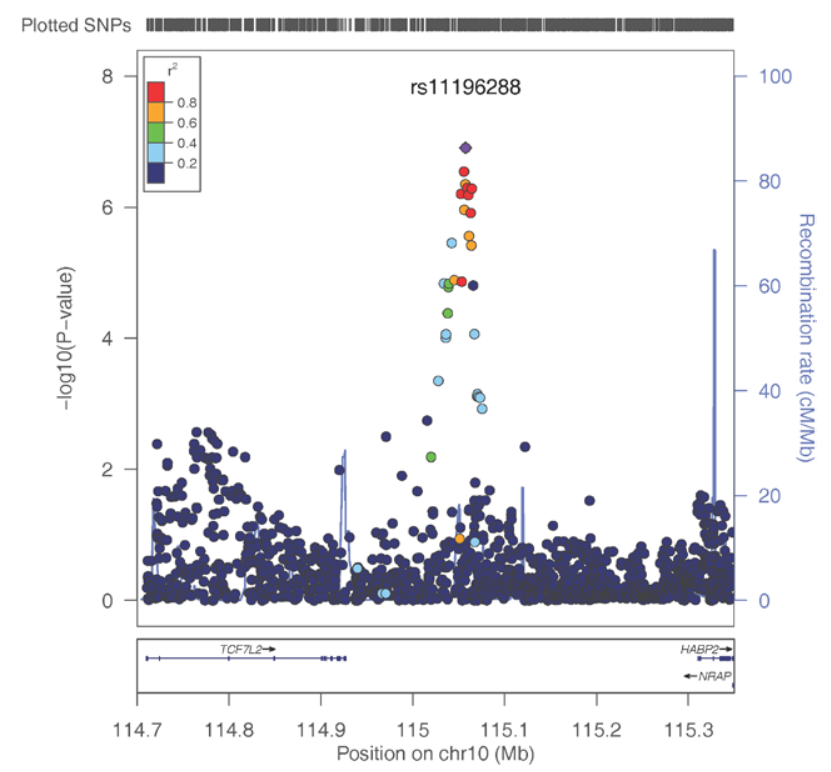

Figure 2. Regional plot of the chr10q25.3 locus from transethnic association analysis in the discovery stage. Recombination rate was based on 1000 Genomes EUR data. Plot was generated using LocusZoom software.

values $<5 \times 10^{-6}$ (Figure 1A; Figure IA in the online-only Data Supplement). However, none reached genome-wide significance $\left(P\right.$ value $\left.<5 \times 10^{-8}\right)$. There was no evidence for genomic inflation $(\lambda=1.004)$. The 4 suggestively associated loci, each

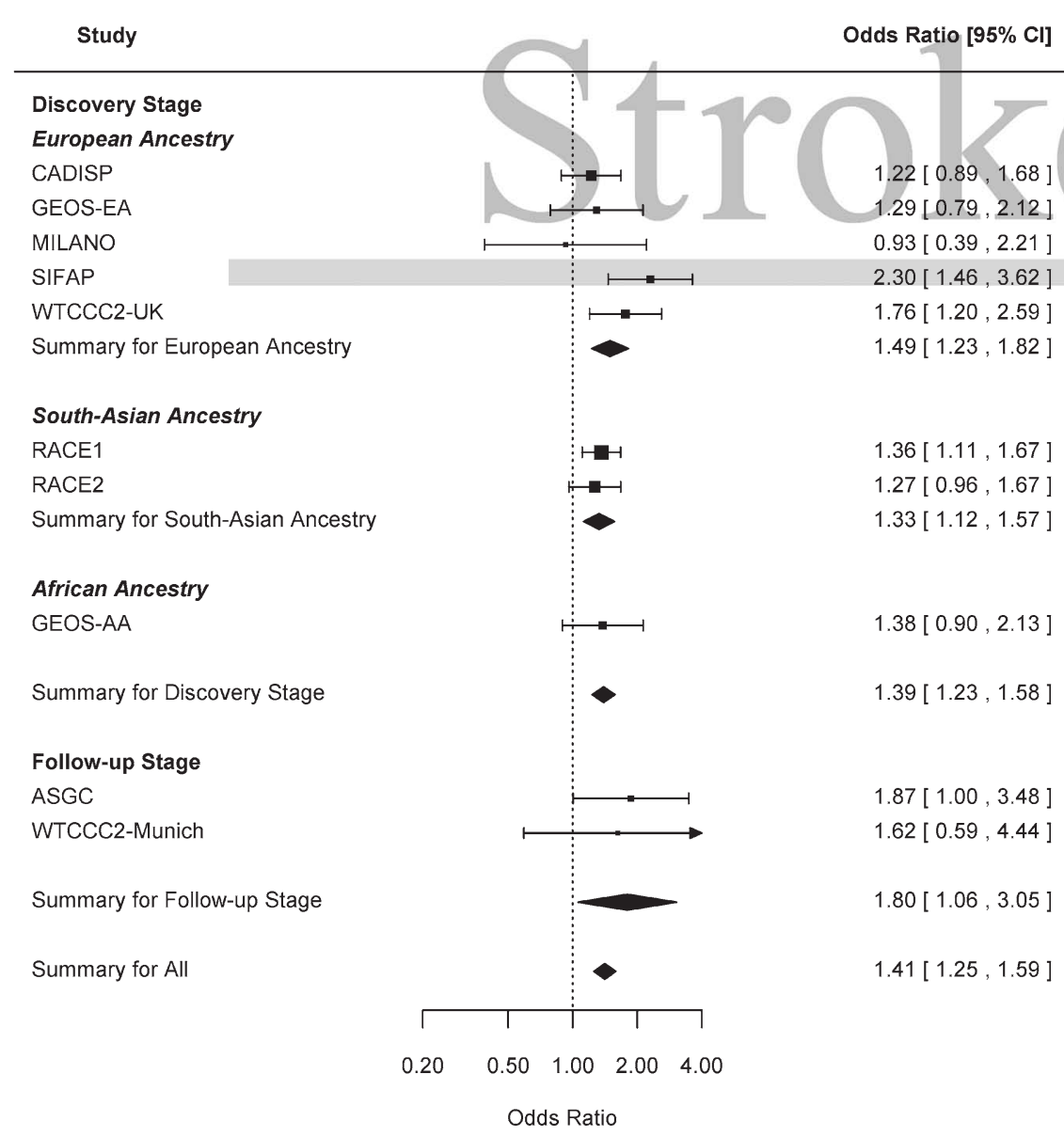

represented by the 2 most significant SNPs, are listed in Table VII in the online-only Data Supplement. Of note, one of these loci includes Factor $V(F 5)$, a well-known stroke candidate gene. ${ }^{10,11}$ Of the 4 loci identified in the European-only metaanalysis, none showed strong evidence for association in the follow-up stage (all stage $2 P$ values $>0.22$; Table VII in the online-only Data Supplement).

Secondary analyses of the associations between rs11196288 and ischemic stroke subtypes based on the 8 studies in the discovery phase revealed nominally significant associations with all 3 major stroke subtypes under the random effect model: cardioembolic stroke $(\mathrm{OR}=1.34 ; P=0.02)$, large artery atherosclerotic stroke $(\mathrm{OR}=1.65 ; P=0.01)$, and small vessel stroke $(\mathrm{OR}=1.57 ; P=0.003)$. For large artery atherosclerotic stroke, there was substantial heterogeneity in effect size between studies $\left(I^{2}=40 \%\right)$. In addition, rs11196288 showed a strong association with undetermined stroke, which accounted for $41 \%$ of all early-onset stroke cases in the discovery phase studies $\left(\mathrm{OR}=1.44, P=3 \times 10^{-5}\right)$. Evidence for association with stroke of other determined pathogenesis could not be evaluated because of limited number of cases. A further genome-wide meta-analysis of stroke subtypes was performed as an exploratory analysis as it was extremely underpowered; this provided no evidence for subtype-specific associations (Table VIII and Figures II and III in the online-only Data Supplement.)

We used the Ensemble Variant Effect Predictor tool to predict function of the index SNPs and SNPs in high LD with them. From these analyses,iwe identified 2 SNPs predicted \begin{tabular}{r|l} 
Heart & Stroke \\
Association & Association.
\end{tabular}

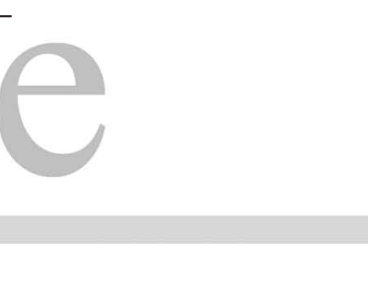

Figure 3. Forest plot of rs11196288 at $10 q 25.3$, including discovery and followup studies, in transethnic analysis. AA indicates African ancestry; ASGC, Australian Stroke Genetics Collaborative; CADISP, Cervical Artery Dissection and Ischemic Stroke Patients; $\mathrm{Cl}$, confidence interval; EA, European ancestry; GEOS, Genetics of Early-Onset Stroke; MILANO, Besta Stroke Study; RACE, Risk Assessment of Cerebrovascular Events Study; SIFAP, Stroke in Young Fabry Patients; and WTCCC2, Wellcome Trust CaseControl Consortium 2. 
to be regulatory region variants that were in high $\mathrm{LD}$ with the index SNP at 10q25. Rs1338423 $\left(r^{2}=0.88\right.$ with $r$ 11196288) and rs4918806 $\left(r^{2}=1\right.$ with rs11196288) both fall in an open chromatin region. Rs4918806 additionally falls in a promoter flanking region and a CCCTC-binding factor binding site.

\section{Associations of Previously Known Stroke-Relevant Loci and the Risk of Early-Onset Ischemic Stroke}

Using the discovery stage samples, we examined associations between early-onset ischemic stroke and 8 loci previously associated with ischemic stroke in GWAS of predominantly European older stroke cases., ${ }^{3,12-18}$ We observed nominally significant associations (ie, $P<0.05$ ) with early-onset ischemic stroke at 4 loci $(A L D H 2, P I T X 2, C D K N 2 B-A S 1$, and $A B O)$ in the European-only analyses (Table IX in the online-only Data Supplement). Interestingly, $A B O$ was also associated with undetermined stroke, a predominant stroke subtype in earlyonset stroke patients. In transethnic meta-analysis, SNPs at PITX2 and $A B O$, but not $C D K N 2 B-A S 1$ or $A L D H 2$, showed nominal association with stroke (Table IX in the online-only Data Supplement).

\section{Effect of the 10q25 Locus on Risk of Ischemic Stroke in Older Populations From the METASTROKE Consortium}

We further examined whether the 2 lead SNPs identified in our early-onset stroke GWAS were associated with the risk of ischemic strokes at older age of onset by performing an in silico look-up of association results from the METASTROKE consortium. Of the 15 discovery studies in METASTROKE, 13 had genotyped rs 11196288 and rs4918806, a perfect proxy $\left(r^{2}=1\right)$ for rs61872854. Five of these studies were already included in either the discovery or follow-up stage of the early-onset stroke GWAS, leaving 8 studies for the in silico look-up. Mean age of stroke in these studies ranged from 57.3 to 81.6 years. Study level results were used because individual-level data are not available through METASTROKE. No significant associations were observed for either rs 11196288 $(\mathrm{OR}=1.08,95 \% \quad \mathrm{CI}=0.96-1.22 ; \quad P=0.18) \quad$ or $\quad \mathrm{rs} 4918806$ $(\mathrm{OR}=1.04,95 \% \mathrm{CI}=0.94-1.14 ; P=0.47)$ in the meta-analysis of the 8 studies. However, when ranking these studies by the mean age of stroke cases (Figure 4), the study with youngest mean age (ie, Atherosclerotic Risk in Community [ARIC], mean age onset $=57.3$ years) showed the strongest risk associated with the 2 SNPs $(\mathrm{OR}=1.51)$, while the study with oldest mean age (ie, Cardiovascular Health Study [CHS], mean age onset $=81.6$ years) showed a nonsignificant inverse association with the 2 early-onset stroke-associated SNPs (OR=0.67). Results remained similar when the 1 study with $>30 \%$ of early-onset stroke cases (Heart Protection Study [HPS]) was removed from the analyses (rs11196288: $\mathrm{OR}=1.09,95 \% \mathrm{CI}=0.96-1.23, P=0.18 ; \mathrm{rs} 495366: \mathrm{OR}=1.03$, $95 \% \mathrm{CI}=0.93-1.14, P=0.55)$.

\section{Associations With Plasma FSAP Levels}

Of the 12 SNPs at 10q25 showing suggestive associations with early-onset ischemic stroke, 2 (rs7906302 and rs1338423) had previously been genotyped in SAHLSIS and were tested for association with circulating FSAP levels ( $\mathrm{n}=125$ normolipidemic control subjects). The risk alleles associated with stroke susceptibility were significantly associated with higher FSAP levels at both loci (rs7906302: 15.1 versus $11.7 \mu \mathrm{g} / \mathrm{mL}$ for $(\mathrm{AC}+\mathrm{CC})$ versus AA genotypes; $P=0.026$ and rs 1338423: 15.6 versus $11.7 \mu \mathrm{g} / \mathrm{mL}$ for AG versus AA genotype; $P=0.012$; see Figure 5). The risk allele frequencies for rs7906302 (allele $\mathrm{C}$ ) and rs1338423 (allele G) are 0.04 and 0.03 in SAHLSIS controls, respectively. Both SNPs are in high $\mathrm{LD}\left(r^{2}=0.88\right.$; Table VI in the online-only Data Supplement) with the index SNP rs11196288.

\section{Discussion}

Although a genetic predisposition to stroke is widely acknowledged, our understanding of genetic basis for ischemic stroke is limited. We have focused in this study on early-onset ischemic stroke, a form of stroke for which there may be a genetic enrichment. Our study included a total of 4505 early-onset stroke cases and 21968 controls from 3 ethnic groups, thus making it the largest GWAS of early-onset stroke carried out to date by far.

Our analysis identified a novel locus at 10q25 strongly associated with early-onset ischemic stroke with an estimated $\approx 1.40$-fold increased risk associated with the risk variant. The 10q25 association showed consistent direction of effect in 9 out of the 10 studies, but achieved genome-wide significance only in the combined analyses of discovery and follow-up samples. Further replication of this locus in independent samples is warranted. Despite this limitation, this locus is of great interest because of its proximity to $H A B P 2$. $H A B P 2$ encodes FSAP, an extracellular serine proteinase that cleaves urinary plasminogen activator, coagulation factor VII, and tissue factor pathway inhibitor and helps regulate coagulation, tissue remodeling, and inflammation. ${ }^{19-22}$ Previous studies reported elevated levels of FSAP activity in patients with coronary artery disease ${ }^{23}$ and ischemic stroke. ${ }^{9}$ Rare genetic variants (eg, the Marburg I polymorphism) in $H A B P 2$ have also been associated with increased risk of deep venous thrombosis, ${ }^{24}$ carotid stenosis, ${ }^{25}$ and stroke. ${ }^{26}$ Recent animal studies have also suggested that FSAP activity may modulate stroke-associated brain injury. ${ }^{27}$

Although the locus associated with early-onset ischemic stroke in our study is located in an intergenic region $\approx 253 \mathrm{~kb}$ away from $H A B P 2$, several of the associated SNPs are predicted to have regulatory properties and associate with circulating levels of FSAP, implicating a possible mechanism leading to increased risk of early-onset stroke via $H A B P 2$. Interestingly, the previously known Marburg I polymorphism in $H A B P 2$ (rs7080536) showed no association with early-onset stroke in our analysis (data not shown). Further studies are needed to identify the causal variant(s) tagged by these associated SNPs as well as their functional properties, leading to the increased risk of early-onset stroke. In contrast to most of the previously known stroke-relevant loci, our data are consistent with this 10q25 locus being associated with multiple stroke subtypes, a finding consistent with the possible thrombotic mechanism of $H A B P 2$ that can lead to increased coagulation and, therefore, susceptibility across the different stroke subtypes. 


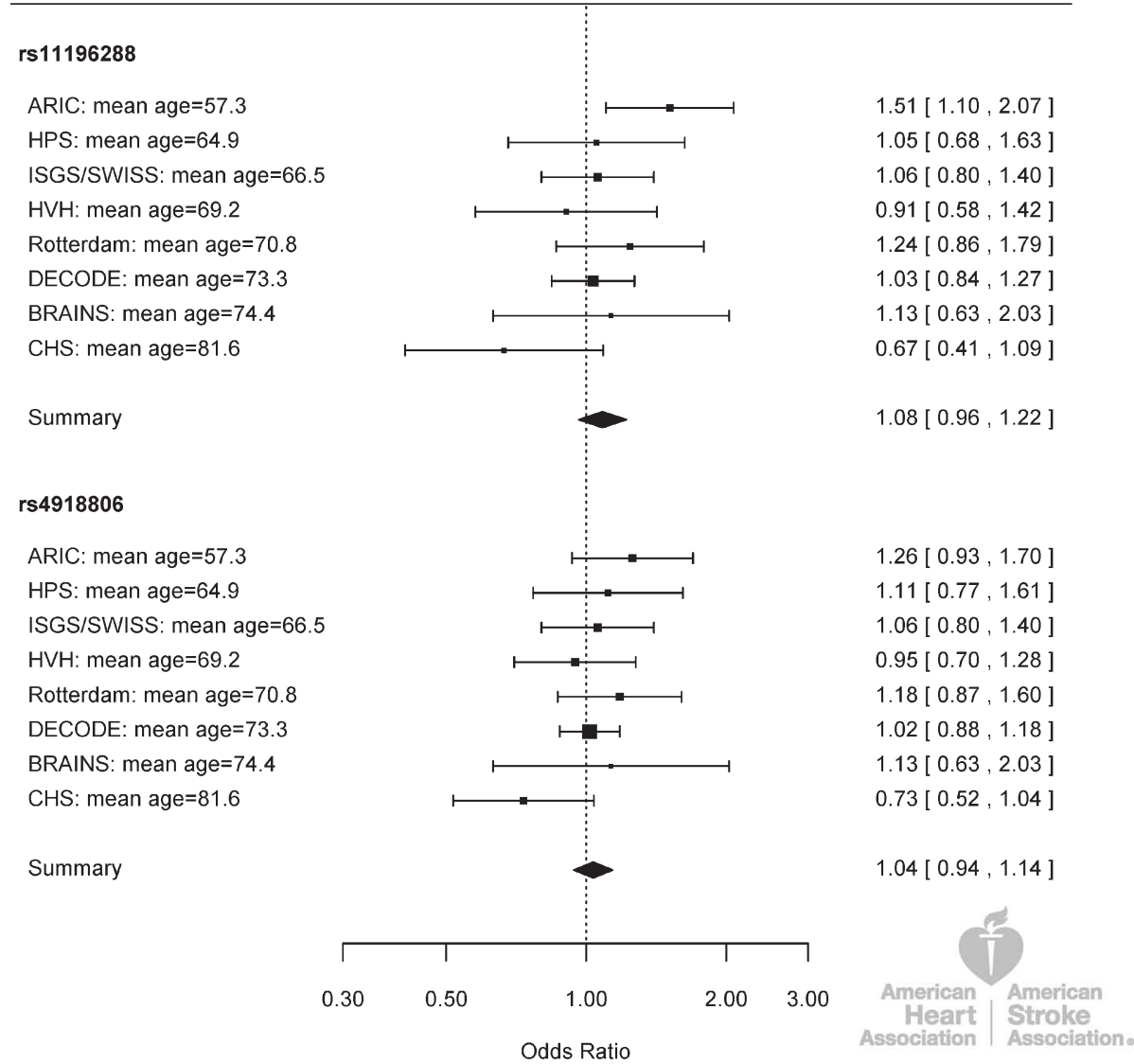

Figure 4. Associations of rs11196288 and rs4918896 at 10q25.3 with risk of stroke in METASTROKE studies, by mean age of stroke cases. ARIC indicates Atherosclerotic Risk in Community; BRAINS, Bio-Repository of DNA in Stroke; CHS, Cardiovascular Health Study; $\mathrm{Cl}$, confidence interval; HPS, Heart Protection Study; HVH, Heart and Vascular Health Study; ISGS/SWISS, Ischemic Stroke Genetics Study/Siblings With Ischemic Stroke Study.

Our study also suggests that the effects of the 10q25 locus may be specific to (or at least more pronounced in) earlyonset stroke because the association was largely absent in METASTROKE studies, which consisted of predominantly older stroke cases. Unfortunately, we did not have access to large case-control cohorts consisting of stroke cases $>60$ years only, and therefore, we were unable to compare the allele frequency of rs11196288 between younger and older stroke cases directly to assess its effect on age of stroke onset. However, even within METASTROKE, there is a hint of an age dependency, with the locus effect appearing strongest in the study with the youngest mean age of onset (ie, ARIC, mean age $=57.3$ years, $\mathrm{OR}=1.51$ ) and weakest in the study with the oldest mean age of stroke onset (ie, CHS, mean age $=81.6$ years, $\mathrm{OR}=0.67)$. An age-dependency for genetic effects would be parallel to prior reports that other risk factors may have large effects in younger versus older-onset stroke. ${ }^{28}$ Further studies on possible interactions between genetic variants and environmental exposures are needed to elucidate how the genetic risk to stroke changes over the life span and in the presence of environmental challenges.

Despite the lack of association between 10q25 and risk of stroke at older age of onset, some of the previously reported stroke loci (identified via studying mainly older stroke cases ${ }^{3,7,13-18}$ ) showed nominal associations with earlyonset stroke in our study, including PITX2 with cardioembolic stroke, $C D K N 2 B-A S 1$ with large artery stroke, $A L D H 2$ with

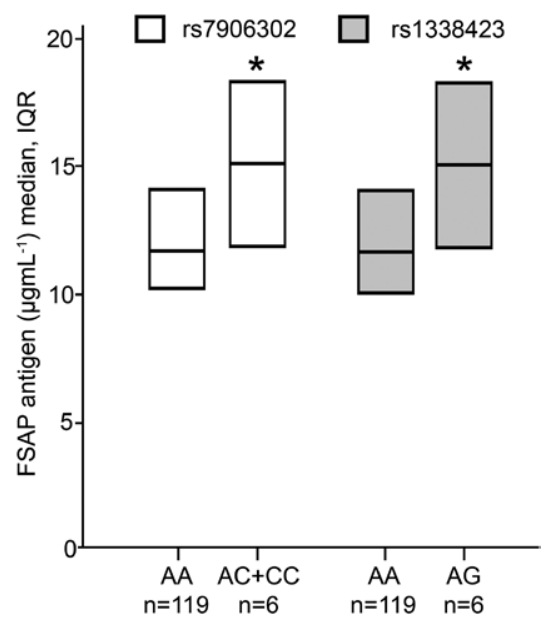

Figure 5. Plasma factor VII activating protease (FSAP) levels are associated with rs7906302 and rs1338423 in normolipidemic controls in Sahlgrenska Academy Study on Ischemic Stroke (SAHLSIS). Median and interquartile range (IQR) of FSAP according to genotype in controls. Differences in logFSAPag levels were calculated with Student's $t$ test. ${ }^{*} P<0.05$. 
overall ischemic stroke, and $A B O$ with cardioembolic, large artery stroke and overall ischemic stroke. Our findings are thus consistent with early-onset and late-onset stroke sharing some of the same genetic susceptibility loci.

Our study was powered to detect an odds ratio of 1.36 for an SNP with MAF=0.05, which was slightly smaller than the effect size $(\mathrm{OR}=1.41)$ actually observed for the associated SNP. However, even including 4500 early-onset stroke cases, we were unable to identify any subtype-specific stroke susceptibility loci in this early-onset stroke population using genome-wide association approach, possibly because of the small number of cases within each stroke subtype. Obtaining sufficient early-onset cases within each stroke subtype remains a significant challenge in future studies, and collaborative efforts will be needed to overcome this limitation. In the European GWAS analysis, we failed to replicate F5, a key protein in the coagulation pathway, as an early-onset stroke susceptibility locus. Previous evidence from candidate gene studies has long suggested that genetic variants of F5 predispose to stroke, the most conspicuous example being the Factor V Leiden (FVL) variant. ${ }^{10,11,29}$ However, a recent large-scale meta-analysis suggested that the reported association between $F V L$ and early-onset ischemic stroke was more pronounced among studies where cases were selected on the basis of having cryptogenic stroke or recruited from a subset of patients referred for a thrombophilic work-up, and the $F V L$-stroke association is much smaller among studies with unselected cases. ${ }^{10}$ This may explain the lack of consistent results observed in our GWAS because cases included in our analyses were unselected, and thus, the genetic effect may be less prominent. Given the complexity of the study populations included in this study, significant phenotypic heterogeneity likely remains among stroke cases even within this early-onset stroke group.

In summary, we have identified a novel locus at $10 \mathrm{q} 25$ associated with all ischemic strokes in young adult population. This locus is located near $H A B P 2$, which encodes an extracellular serine protease involved in coagulation, fibrinolysis, and even inflammatory pathways, suggesting a plausible biological mechanism leading to increased risk of stroke. This locus did not appear to have a significant effect in older cases, indicating this may be a genetic susceptibility locus for earlyonset stroke. Further replication of the 10q25 locus and additional studies investigating the potential age of onset effect are needed.

\section{Sources of Funding}

The Atherosclerotic Risk in Community (ARIC): National Institutes of Health (NIH) contracts: HHSN268201100005C, HHSN268201100006C, HHSN268201100007C, HHSN268201100008C, HHSN268201100009C, HHSN268201100010C, HHSN268201100011C, HHSN268201100012C, U01HG004402; HHSN268200625226C, N01-HC-55015, N01HC-55016, N01-HC-55018, N01-HC-55019, N01-HC-55020, N01HC-55021, N01-HC-55022, and U01-HL096917. NIH grants: R01HL087641, R01HL59367, R01HL086694, R01HL087641, UL1RR025005, and HL093029. The Australian Stroke Genetics Collaborative (ASGC) grants: the Australian National Health and Medical Research Council (project 569257) and the Australian National Heart Foundation (grant G-04S-1623). Elizabeth Holliday supported by a fellowship (100071) from the Australian Heart Foundation and National Stroke Foundation. Bio-Repository of
DNA in Stroke (BRAINS) support: the Henry Smith Charity, the UK-India Education Research Institutive from the British Council, and a Senior Fellowship from the UK Department of Health awarded to Dr Pankaj Sharma. The Cervical Artery Dissection and Ischemic Stroke Patients (CADISP) study Institutional: Inserm, Lille 2 University, Institut Pasteur de Lille, and Lille University Hospital. Funding: the European Regional Development Fund (FEDER funds) and Région Nord-Pas de Calais in the frame of Contrat de Projets Etat-Region 2007-2013 Région Nord-Pas-de-Calais - Grant No 09120030, Centre National de Genotypage, Emil Aaltonen Foundation, Paavo Ilmari Ahvenainen Foundation, Helsinki University Central Hospital Research Fund, Helsinki University Medical Foundation, Päivikki and Sakari Sohlberg Foundation, Aarne Koskelo Foundation, Maire Taponen Foundation, Aarne and Aili Turunen Foundation, Lilly Foundation, Alfred Kordelin Foundation, Finnish Medical Foundation, Orion Farmos Research Foundation, Maud Kuistila Foundation, the Finnish Brain Foundation, Biomedicum Helsinki Foundation, Projet Hospitalier de Recherche Clinique Régional, Fondation de France, Génopôle de Lille, Adrinord, Basel StrokeFunds, Käthe-Zingg-Schwichtenberg-Fonds of the Swiss Academy of Medical Sciences, Swiss Heart Foundation. Stéphanie Debette is a recipient of a "Chaire d'Excellence Junior" grant from the Agence Nationale de la Recherche and is supported by a grant from the Fondation Leducq. V. Thijs was supported by a Fundamental Clinical Research Fellowship from FWO Flanders. The Cardiovascular Health Study (CHS) NIH contracts: HHSN268201200036C, HHSN268200800007C, N01HC55222, N01HC85079, N01HC85080, N01HC85081, N01HC85082, N01HC85083, N01HC85086. NIH grants: U01HL080295, R01HL087652, R01HL105756, R01HL103612, R01HL120393, R01AG023629, and R01DK063491. Genotyping: the National Center for Advancing Translational Sciences, Clinical \& Translational Science Institute grant UL1TR000124. The deCODE coronary artery disease/myocardial infarction Study NIH grant: R01HL089650. deCODE Genetics supported, in part, through a grant from the European Community's Seventh Framework Programme (FP7/2007-2013), the European Network for Genetic and Genomic Epidemiology (ENGAGE) project grant agreement HEALTH-F4-2007 to 201413. The Genetics of Early-Onset Stroke (GEOS) study NIH grants: U01-HG004436, P30DK072488, U01-NS069208, R01-NS45012, U01-NS069208, U01HG004438, U01-HG004446, and the Baltimore Geriatrics Research, Education, and Clinical Center of the Department of Veterans Affairs. Yu-Ching Cheng was supported by a Career Development Award from Department of Veterans Affairs. Dr Cole was supported by research grants from the Department of Veterans Affairs and the American Heart Association (15GPSPG23770000). Heart Protection Study (HPS; ISRCTN48489393): the UK Medical Research Council, British Heart Foundation (BHF), Merck \& Co (manufacturers of simvastatin), and Roche Vitamins Ltd (manufacturers of vitamins). Genotyping supported by a grant to Oxford University and Centre National de Génotypage from Merck \& Co. Dr Hopewell was supported by the British Heart Foundation (FS/14/55/30806). The Heart and Vascular Health Study (HVH) NIH grants R01-HL085251 and R01-HL073410. The Ischemic Stroke Genetics Study (ISGS)/ Siblings With Ischemic Stroke Study (SWISS) NIH grants: R01NS42733 and R01-NS39987 and NIH intramural project Z01AG000954. ISGS/SWISS used samples and clinical data from the NIH-National Institute of Neurological Disorders and Stroke Human Genetics Resource Center DNA and Cell Line Repository (http://ccr. coriell.org/ninds) and human subjects protocol numbers 2003-081 and 2004-147. Controls for ISGS/SWISS obtained from the Baltimore Longitudinal Study of Aging with support from the NIA Intramural Research Program (Z01-AG000015-50, human subjects protocol number 2003-078). The MILANO study supported by Annual Research Funding of the Italian Ministry of Health (grants: RC-2007/LR6, RC-2008/LR6; RC-2009/LR8; RC-2010/LR8). The Sahlgrenska Academy Study of Ischemic Stroke (SAHLSIS) the Swedish Research Council, the Swedish state, and the Swedish Heart and Lung Foundation. Sandip Kanse acknowledges funding from Behring Roentgen Stiftung, Deutscheforschungsgemeinschaft and Helse Sør-Øst. Stroke in Young Fabry Patients (SIFAP) NIH grant: 
U01-HG004436. Control subjects for SIFAP provided by the KORA (Cooperative Health Research in the Region of Augsburg [Germany]) study (see below, WTCCC2-Munich). Risk Assessment of Cerebrovascular Events Study (RACE). Grants: to the University of Cambridge from the Wellcome Trust, British Heart Foundation, UK Medical Research Council, Pfizer, Novartis, and Merck and NIH Grant U01-HG004436. The Rotterdam study Institutional: The Netherlands Organization of Scientific Research (175.010.2005.011), the Netherlands Genomics Initiative/Netherlands Organization for Scientific Research Netherlands Consortium for Healthy Ageing (050-060-810), Nederlandse Hartstichting (2009B102), the Erasmus Medical Center and Erasmus University, Rotterdam, the Netherlands Organization for Health Research and Development, the Research Institute for Diseases in the Elderly, the Ministry of Education, Culture, and Science, the Ministry for Health, Welfare, and Sports, the European Commission, and the Municipality of Rotterdam to the Rotterdam Study. The Wellcome Trust Case-Control Consortium 2 (WTCCC2): WTCCC2-UK: the Wellcome Trust (085475/B/08/Z and 085475/Z/08/Z and WT084724MA), The Stroke Association, the Medical Research Council (grants WT095219MA and G1001799), Dunhill Medical Trust, National Institute of Health Research (NIHR), the NIHR Biomedical Research Centre, the Binks Trust, the Scottish Funding Council and the Chief Scientist Office. P.M. Rothwell has a Wellcome Trust Senior Investigator Award and an NIHR Senior Investigator Award, and C. Sudlow has a Wellcome Trust clinician scientist award. WTCCC2-Munich: Grants: the German Federal Ministry of Education and Research in the context of the e:Med program (e:AtheroSysMed) and the FP7 European Union project CVgenes-AT-target (261123) to M. Dichgans and from the Vascular Dementia Research Foundation. The KORA study was initiated and financed by the Helmholtz Zentrum München-German Research Center for Environmental Health. Additional KORA support was from the Munich Center of Health Sciences (MC-Health), Ludwig-Maximilians-Universität, as part of LMUinnovativ. WTCCC Immunochip: supported by the WTCCC2. Lund Stroke Register: the Swedish Research Council, The Swedish Heart-Lung Foundation, Region Skåne, the Freemasons Lodge of Instruction EOS in Lund, King Gustaf V, and Queen Victoria's Foundation, Lund University, the Swedish Stroke Association, Region Skåne Competence Centre (RSKC Malmö), and Labmedicin Skåne, University and Regional Laboratories Region Skåne, Sweden. Investigator support: Stroke Association Project Grant TSA-2013/01 (Matthew Traylor), the National Research Leading Center, Jagiellonian University, Krakow, Poland (Agnieszka Slowik), and NIHR Senior Investigator award (Hugh Markus).

\section{Disclosures}

Drs Kittner, Longstreth, and Worrall are supported by research grants from National Institutes of Health (NIH). Dr Worrall is Deputy Editor for AAN/Neurology. Dr Cole is supported by a research grant from the Department of Veterans Affairs. Dr Boncoraglio is supported by a research grant from the Fondazione IRCCS Istituto Neurologico Carlo Besta. Dr Metso is supported by grants from the Finnish Medical Foundation, the Orion Farmos Research Foundation, the Maud Kuistila Memorial Foundation, and the Emil Aaltonen Foundation. Dr Danesh serves on advisory boards for Novartis, Merck Sharp \& Dohme UK, Sanofi, the Medical Research Council, and Wellcome Trust and is a consultant for Takeda. The other authors report no conflicts.

\section{References}

1. Go AS, Mozaffarian D, Roger VL, Benjamin EJ, Berry JD, Blaha MJ, et al; American Heart Association Statistics Committee and Stroke Statistics Subcommittee. Heart disease and stroke statistics-2014 update: a report from the American Heart Association. Circulation. 2014;129:e28-e292. doi: 10.1161/01.cir.0000441139.02102.80.

2. Bevan S, Traylor M, Adib-Samii P, Malik R, Paul NL, Jackson C, et al. Genetic heritability of ischemic stroke and the contribution of previously reported candidate gene and genomewide associations. Stroke. 2012;43:3161-3167. doi: 10.1161/STROKEAHA.112.665760.
3. Holliday EG, Maguire JM, Evans TJ, Koblar SA, Jannes J, Sturm JW, et al; Australian Stroke Genetics Collaborative; International Stroke Genetics Consortium; Wellcome Trust Case Control Consortium 2. Common variants at $6 \mathrm{p} 21.1$ are associated with large artery atherosclerotic stroke. Nat Genet. 2012;44:1147-1151. doi: 10.1038/ng.2397.

4. Cheng YC, Cole JW, Kittner SJ, Mitchell BD. Genetics of ischemic stroke in young adults. Circ Cardiovasc Genet. 2014;7:383-392. doi: 10.1161/CIRCGENETICS.113.000390.

5. Falcone GJ, Malik R, Dichgans M, Rosand J. Current concepts and clinical applications of stroke genetics. Lancet Neurol. 2014;13:405-418. doi: 10.1016/S1474-4422(14)70029-8.

6. Howie BN, Donnelly P, Marchini J. A flexible and accurate genotype imputation method for the next generation of genome-wide association studies. PLoS Genet. 2009;5:e1000529. doi: 10.1371/journal. pgen. 1000529.

7. Traylor M, Farrall M, Holliday EG, Sudlow C, Hopewell JC, Cheng YC, et al; Australian Stroke Genetics Collaborative, Wellcome Trust Case Control Consortium 2 (WTCCC2); International Stroke Genetics Consortium. Genetic risk factors for ischaemic stroke and its subtypes (the METASTROKE collaboration): a meta-analysis of genome-wide association studies. Lancet Neurol. 2012;11:951-962. doi: 10.1016/ S1474-4422(12)70234-X.

8. Jood K, Ladenvall C, Rosengren A, Blomstrand C, Jern C. Family history in ischemic stroke before 70 years of age: the Sahlgrenska Academy Study on Ischemic Stroke. Stroke. 2005;36:1383-1387. doi: 10.1161/01. STR.0000169944.46025.09.

9. Hanson E, Kanse SM, Joshi A, Jood K, Nilsson S, Blomstrand C, et al. Plasma factor VII-activating protease antigen levels and activity are increased in ischemic stroke. J Thromb Haemost. 2012;10:848-856. doi: 10.1111/j.1538-7836.2012.04692.x.

10. Hamedani AG, Cole JW, Mitchell BD, Kittner SJ. Meta-analysis of factor V Leiden and ischemic stroke in young adults: the importance of case ascertainment. Stroke.2010;41:1599-1603. doi: 10.1161/ STROKEAHA.110.581256.

11. Xin XY, Song YY, Ma JF, Fan $C N$, Ding JQ, Yang GY, et al. Gene polymorphisms and risk of adult early-onset ischemic stroke: A meta-analysis. Thromb Res. 2009;124:619-624. doi: 10.1016/j. thromres.2009.07.007.

12. Ikram MA, Seshadri S, Bis JC, Fornage M, DeStefano AL, Aulchenko YS, et al. Genomewide association studies of stroke. $N$ Engl J Med. 2009;360:1718-1728. doi: 10.1056/NEJMoa0900094.

13. Kilarski LL, Achterberg S, Devan WJ, Traylor M, Malik R, Lindgren A, et al; GARNET Collaborative Research Group, Wellcome Trust Case Control Consortium 2, Australian Stroke Genetic Collaborative, the METASTROKE Consortium, and the International Stroke Genetics Consortium. Meta-analysis in more than 17,900 cases of ischemic stroke reveals a novel association at 12q24.12. Neurology. 2014;83:678-685. doi: 10.1212/WNL.0000000000000707.

14. Gretarsdottir S, Thorleifsson G, Manolescu A, Styrkarsdottir U, Helgadottir A, Gschwendtner A, et al. Risk variants for atrial fibrillation on chromosome 4q25 associate with ischemic stroke. Ann Neurol. 2008;64:402-409. doi: 10.1002/ana.21480.

15. Gudbjartsson DF, Holm H, Gretarsdottir S, Thorleifsson G, Walters GB, Thorgeirsson G, et al. A sequence variant in ZFHX3 on 16q22 associates with atrial fibrillation and ischemic stroke. Nat Genet. 2009;41:876-878. doi: 10.1038/ng.417.

16. Gschwendtner A, Bevan S, Cole JW, Plourde A, Matarin M, Ross-Adams $\mathrm{H}$, et al; International Stroke Genetics Consortium. Sequence variants on chromosome 9p21.3 confer risk for atherosclerotic stroke. Ann Neurol. 2009;65:531-539. doi: 10.1002/ana.21590.

17. International Stroke Genetics Consortium, Wellcome Trust Case Control Consortium, Bellenguez C, Bevan S, Gschwendtner A, Spencer CC, Burgess AI, Pirinen M, et al. Genome-wide association study identifies a variant in HDAC9 associated with large vessel ischemic stroke. Nat Genet. 2012;44:328-333. doi: 10.1038/ng.1081.

18. Williams FM, Carter AM, Hysi PG, Surdulescu G, Hodgkiss D, Soranzo $\mathrm{N}$, et al; EuroCLOT Investigators; Wellcome Trust Case Control Consortium 2; MOnica Risk, Genetics, Archiving and Monograph; MetaStroke; International Stroke Genetics Consortium. Ischemic stroke is associated with the ABO locus: the EuroCLOT study. Ann Neurol. 2013;73:16-31. doi: 10.1002/ana.23838.

19. Kanse SM, Etscheid M. Factor VII activating protease. Single nucleotide polymorphisms light the way. Hamostaseologie. 2011;31:174-176, 177. doi: 10.5482/ha-1159. 
20. Parahuleva MS, Maj R, Hölschermann H, Parviz B, Abdallah Y, Erdogan A, et al. Regulation of monocyte/macrophage function by factor VII activating protease (FSAP). Atherosclerosis. 2013;230:365-372. doi: 10.1016/j.atherosclerosis.2013.08.007.

21. Römisch J, Feussner A, Vermöhlen S, Stöhr HA. A protease isolated from human plasma activating factor VII independent of tissue factor. Blood Coagul Fibrinolysis. 1999;10:471-479.

22. Kannemeier C, Feussner A, Stöhr HA, Weisse J, Preissner KT, Römisch J. Factor VII and single-chain plasminogen activator-activating protease: activation and autoactivation of the proenzyme. Eur $J$ Biochem. 2001;268:3789-3796.

23. Parahuleva MS, Hölschermann H, Zandt D, Pons-Kühnemann J, Parviz $\mathrm{B}$, Weiskirchen R, et al. Circulating factor VII activating protease (FSAP) is associated with clinical outcome in acute coronary syndrome. Circ J. 2012;76:2653-2661.

24. Ahmad-Nejad P, Dempfle CE, Weiss C, Bugert P, Borggrefe M, Neumaier $\mathrm{M}$. The G534E-polymorphism of the gene encoding the factor VII-activating protease is a risk factor for venous thrombosis and recurrent events. Thromb Res. 2012;130:441-444. doi: 10.1016/j.thromres.2012.02.009.
25. Willeit J, Kiechl S, Weimer T, Mair A, Santer P, Wiedermann CJ, et al. Marburg I polymorphism of factor VII-activating protease: a prominent risk predictor of carotid stenosis. Circulation. 2003;107:667-670.

26. Trompet S, Pons D, Kanse SM, de Craen AJ, Ikram MA, Verschuren JJ, et al. Factor VII activating protease polymorphism (G534E) is associated with increased risk for stroke and mortality. Stroke Res Treat. 2011;2011:424759. doi: 10.4061/2011/424759.

27. Joshi AU, Orset C, Engelhardt B, Baumgart-Vogt E, Gerriets T, Vivien D, et al. Deficiency of Factor VII activating protease alters the outcome of ischemic stroke in mice. Eur J Neurosci. 2015;41:965-975. doi: 10.1111/ejn.12830.

28. Asplund K, Karvanen J, Giampaoli S, Jousilahti P, Niemelä M, Broda G, et al; MORGAM Project. Relative risks for stroke by age, sex, and population based on follow-up of 18 European populations in the MORGAM Project. Stroke. 2009;40:2319-2326. doi: 10.1161/STROKEAHA.109.547869.

29. Hamedani AG, Cole JW, Cheng Y, Sparks MJ, O'Connell JR, Stine OC, et al. Factor V leiden and ischemic stroke risk: the Genetics of Early Onset Stroke (GEOS) study. J Stroke Cerebrovasc Dis. 2013;22:419423. doi: 10.1016/j.jstrokecerebrovasdis.2011.10.007.

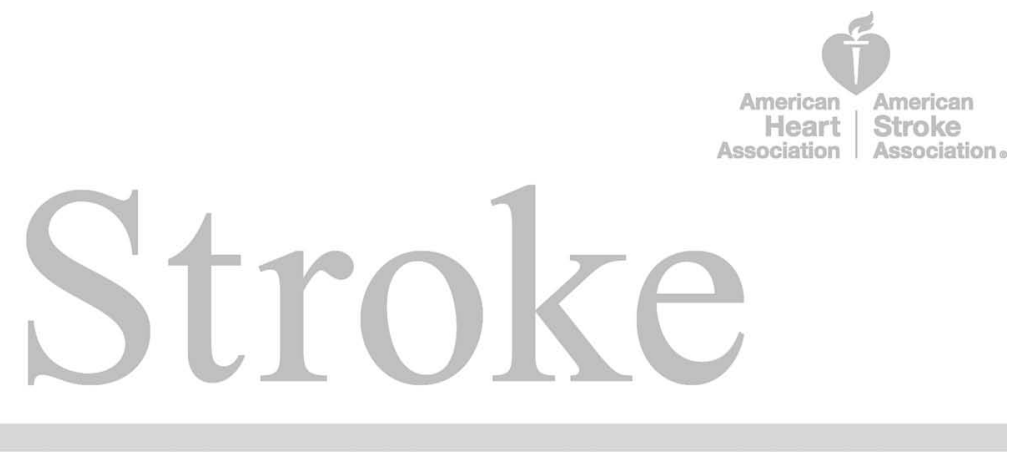




\section{SUPPLEMENTAL MATERIAL}

Cheng et al. Genome-wide association analysis of young onset stroke identifies a locus on chromosome 10q25 near HABP2 


\section{Table of Contents}

1. Details of the Discovery and Follow-up Stages for GWAS .............................................................

2. Study-specific GWAS of the Discovery Cohorts ........................................................................

3. Testing for association of index SNPs with FSAP levels in the SAHLSIS .....................................

4. Description of Stage 1 and Stage 2 Studies ...............................................................................

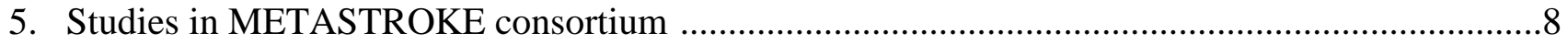

6. The Sahlgrenska Study of Ischemic Stroke (SAHLSIS) …….......................................................12

7. Supplemental Tables

Supplemental Table I. Study design and characteristics of participating studies in the

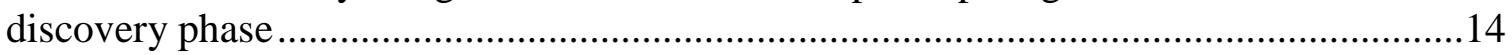

Supplemental Table II. Study design and characteristics of participating studies in the validation phase ..........................................................................................................16

Supplemental Table III. Genotyping and analysis methods used by each participating studies in discovery phase...............................................................................................17

Supplemental Table IV. Genotyping and analysis methods used in the validation studies

Supplemental Table V. Study design and characteristics of METASTROKE cohorts .................20

Supplemental Table VI. SNPs with suggestive associations with early-onset ischemic stroke and their proxy SNPs in chr10 region ...................................................................21

Supplemental Table VII. Top associated SNPs for early onset stroke ..........................................22

Supplemental Table VIII. Top associated SNPs in GWAS analysis of stroke subtypes ...............23

Supplemental Table IX. SNPs previously associated with ischemic stroke (and/or ischemic stroke subtypes) and their associations with early-onset stroke

8. Supplemental Figures

Supplemental Figure I. QQ plot of (A) European-only meta-analysis and (B) transethnic meta-analysis

Supplemental Figure II. European-ancestry GWAS results of stroke subtypes (A) cardioembolic, (B) large artery atherosclerotic, (C) small vessel stroke and (D) undetermined.

Supplemental Figure III. Trans-ethnic GWAS results of stroke subtypes (A) cardioembolic, (B) large artery atherosclerotic, (C) small vessel stroke and (D) undetermined.

9. Supplemental References 


\section{Details of the Discovery and Follow-up Stages for GWAS}

Discovery GWAS Stage (Stage 1). The Discovery stage for the GWAS meta-analysis included a total of 4,505 early-onset cases and 21,968 controls from 6 studies: Cervical Artery Dissections and Ischemic Stroke Patients study (CADISP), Genetics of Early-onset Stroke study (GEOS), Milano study (MILANO), Stroke in Young Fabry Patients (SIFAP), Risk Assessment of Cerebrovascular Events Study (RACE) and UK samples from Wellcome Trust Case Control Consortium 2 (WTCCC2-UK). Four of these studies (CADISP, MILANO, SIFAP, WTCCC2-UK) included individuals of European ancestry only, while RACE included individuals of South-Asian ancestry from Pakistan and GEOS, which recruited participants from the Greater-Baltimore Washington Area, USA, included individuals of both European ancestry and African Americans. All studies used a case-control study design. External controls (genotyped separately from the cases) were used for three studies: SIFAP (controls from Cooperative Health Research in the Augsburg Region ["Kooperative Gesundheitsforschung in der Region Augsburg"], KORA), RACE (controls from the Pakistan Risk of Myocardial Infarction Study [PROMIS]), and WTCCC2-UK (controls from the 1958 British Birth cohort and the UK Blood Service control group). RACE cases were genotyped in two phases (RACE1 and RACE2) and thus were analyzed separately and then meta-analyzed together to provide RACE study-specific estimates. Studyspecific subject inclusion/exclusion criteria are provided in the Supplementary Data, and summary of study characteristics, including their sample size, are listed in Table 1 and Supplemental Table I.

Follow-up Stage (Stage 2). The Follow-up stage included a total of 1,003 independent, earlyonset cases and 7,745 controls from the Australia Stroke Genetics Collaborative (ASGC), Munich samples from WTCCC2 (Munich) and the WTCCC Immunochip Study (Immunochip). All three studies were of European ancestry and used the case-control study design, and subjects included in the Followup stage were independent of those included in the Discovery. The ASGC and Munich studies were genotyped using whole-genome array while WTCCC Immunochip Study were genotyped using Illumina ImmunoChip.

Ischemic stroke was defined according to predefined study-specific criteria, generally as a focal neurological deficit lasting greater than 24 hours or, if lasting less than 24 hours, with neuroimaging evidence. The majority of cases were first-ever strokes. Stroke subtypes were defined according to the Trial of Org 10172 in Acute Stroke Treatment (TOAST) criteria. ${ }^{1}$

\section{Study-specific GWAS of the Discovery Cohorts}

The 6 Discovery cohorts included 3 studies with internal controls (GEOS, CADISP, and MILANO) and 3 studies with external controls (SIFAP, RACE, and WTCCC2-UK), the latter including external controls by design in order to maximize the number of cases that could be genotyped. All studies were genotyped using whole-genome SNP arrays from Illumina (San Diego, CA, USA). Extensive quality control was carried out at each site at both the sample and SNP level. Study samples were removed from analyses if they had low genotyping call rates, exhibited mismatches between genetic and reported genders or relatedness, or were outliers from the population on the basis of principal component analysis of SNPs. SNPs were excluded prior to imputation if they had high missing call rates (missing rate $>5 \%$ ), were monomorphic, or deviated from Hardy-Weinberg equilibrium (HWE $\mathrm{p}<0.0001$ for most studies). Detailed information about the genotyping platforms, genotype cleaning 
procedures, imputation process, and association analysis modeling is described in Supplemental Tables III (Discovery phase) and IV (Follow-up phase).

Additional SNP level QC was performed for the studies with external controls to ensure that artifactual differences in allele frequencies between cases and controls did not arise due to differences in genotyping performance between genotyping centers. Within each study, cases and controls were merged for a second round of SNP cleaning to remove SNPs with differential missingness between cases and controls and to check for cyptic relatedness. In the GEOS, SIFAPS, and RACE I studies, genotyping concordance rates between cases and controls were evaluated by re-genotyping 30 control samples that had been previously genotyped along with the cases, after which SNPs with $\geq 1$ discordant genotype in a sample were removed from analysis. Principal components were calculated within the merged cases and control groups and outlier samples were removed from analysis. After QC, a genomewide association study (GWAS) was performed within each study to check genomic inflation and ensure that QC had successfully removed false associations potentially resulting from the study design. Lambda values across the studies revealed no evidence for genomic inflation (lambdas: 0.98, 0.98, 1.05, 1.01, and 1.02 for GEOS-EUR, GEOS-AFR, SIFAP, RACE I, and WTCCC2-UK, respectively).

\section{Testing for association of index SNPs with FSAP levels in the SAHLSIS}

SAHLSIS participants had previously been genotyped on the Illumina Human OmniExpress 750K array at the Broad Institute at Harvard Medical School (Boston, USA). This array included two SNPs (rs7906302 and rs1338423) that were in high linkage disequilibrium (LD) with the young onset strokeassociated SNP $\left(r^{2}=0.88\right.$; $D^{\prime}=1$ for both SNPs with the index SNP). These two SNPs were in high LD with each other $\left(r^{2}=0.77\right)$. Because the number of subjects with two copies of the minor allele of rs7906302 was small (2 individuals), the minor allele was treated as absent (AA) versus present (AC + CC). For rs1338423, no individuals had two copies of the minor allele (G) and comparisons were therefore made between the AA and AG genotypes.

\section{Description of Stage 1 and Stage 2 Studies}

\section{Australian Stroke Genetics Collaborative (ASGC)}

ASGC stroke cases comprised stroke patients of European ancestry who were admitted to four clinical centers across Australia (The Neurosciences Department at Gosford Hospital, Gosford; the Neurology Department at John Hunter Hospital, Newcastle; The Queen Elizabeth Hospital, Adelaide; and the Royal Perth Hospital, Perth) between 2003 and 2008. Stroke was defined by World Health Organization criteria as a sudden focal neurological deficit of vascular origin, lasting more than $24 \mathrm{~h}$ and confirmed by imaging, such as computerized tomography (CT) and/or magnetic resonance imaging (MRI) brain scan. Other investigative tests such as electrocardiogram, carotid Doppler and trans-esophageal echocardiogram were conducted to define ischemic stroke mechanism as clinically appropriate. Cases were excluded from participation if they were aged $<18$ years, were diagnosed with hemorrhagic stroke or had transient ischemic attack rather than ischemic stroke or if they were unable to undergo baseline brain imaging. On the basis of these criteria, a total of 1,230 ischemic stroke cases were included in the current study. Ischemic stroke subtypes were assigned using TOAST criteria on the basis of clinical, imaging and risk factor data. 
ASGC controls were participants in the Hunter Community Study (HCS), a population-based cohort of individuals aged 55-85 years, predominantly of European ancestry and residing in the Hunter Region in New South Wales, Australia. Participants were randomly selected from the New South Wales State electoral roll and were contacted by mail between 2004 and 2007. Consenting participants completed five detailed self-report questionnaires and attended the HCS data collection center, at which time a series of clinical measures were obtained. A total of 1,280 HCS participants were genotyped for the current study.

All study participants gave informed consent for participation in genetic studies. Approval for the individual studies was obtained from the relevant institutional ethics committees.

\section{Cervical Artery Dissection and Ischemic Stroke Patients (CADISP)}

The CADISP Study aims primarily at identifying genetic and environmental risk factors for cervical artery dissection (CeAD), a major cause of ischemic stroke in young adults. We included 942 CeAD patients in the CADISP study in 2004-2009 (CADISP-1; 170 Finns and 772 non-Finnish Europeans). Additional 451 CeAD patients of European origin were recruited in 2008-2010, exclusively for the CADISP-genetics project, in some CADISP centers and additional European and US centers (CADISP2). To assess the specificity of risk factors for CeAD, we also recruited 583 patients with an IS attributable to other causes (non-CeAD IS, 162 Finns and 421 non-Finnish Europeans from Belgium, France, Germany, Italy, and Switzerland), frequency-matched on age, sex and geographical origin with CADISP-1 CeAD patients. Of these, a total of 555 non-CeAD IS patients aged $<60$ years, who were successfully genotyped and met genotyping quality control criteria, were available for the present analysis. The abstracted hospital records of cases were reviewed and adjudicated for IS subtype by a neurologist in each participating center. Each item required for the subtype classification was also recorded in a standardized fashion. Based on this, IS subtypes were then centrally readjudicated by a panel of neurologists, in agreement with the TOAST system ${ }^{1}$, using the more detailed subtype description from Ay et al. ${ }^{2}$ DNA samples were genotyped on an Illumina Human610-Quad or Human660W-Quad BeadChip ${ }^{\circledR}$ at the Centre National de Génotypage [CNG], Evry, France. The majority of controls ( $N=9,046$, of which 74 Finns and 8,972 non-Finnish Europeans) were selected from an anonymized control genotype database at the CNG, in order to match cases for ethnic background, based on principal component analysis. European reference samples from the genotype repository at the CNG were also analyzed simultaneously to provide improved geographical resolution. Additional Finnish controls were recruited within the CADISP study, both from the general population and among spouses and unrelated friends of CADISP patients, within the Helsinki area. A total of 234 individuals were eligible for genotyping at the CNG. Of these, 213 individuals who were genotyped successfully and met quality control criteria were available for the present analysis. Individuals were excluded if they were unexpected duplicates, gender discrepancy and unexpected relatedness. After quality control, we performed genotype imputation to the nonmonomorphic SNPs described in the 1000 genomes phase I v3 reference panel.

\section{Genetics of Early-onset Stroke Study (GEOS)}

GEOS is a population-based case-control study designed to identify genes associated with early-onset ischemic stroke and to characterize interactions of identified stroke genes and/or SNPs with environmental risk factors. ${ }^{3 ;}$ Participants were recruited from the greater Baltimore-Washington area in 4 different time periods: Stroke Prevention in Young Women-1 (SPYW-1) conducted from 1992- 
1996, Stroke Prevention in Young Women-2 (SPYW-2) conducted from 2001-2003, Stroke Prevention in Young Men (SPYM) conducted from 2003-2007, and Stroke Prevention in Young Adults (SPYA) conducted in 2008. Case participants were hospitalized with a first cerebral infarction identified by discharge surveillance from one of the 59 hospitals in the greater Baltimore-Washington area and direct referral from regional neurologists. The abstracted hospital records of cases were reviewed and adjudicated for ischemic stroke subtype by a pair of neurologists according to previously published procedures with disagreements resolved by a third neurologist. The ischemic stroke subtype classification system retains information on all probable and possible causes, and is reducible to the more widely used TOAST system that assigns each case to a single category. Control participants without a history of stroke were identified by random-digit dialing and were balanced to cases by age and region of residence in each recruitment periods. Genomic DNA was isolated from a variety of sample types, including cell line, whole blood, mouth wash and buccal swab. Samples were genotyped at the Johns Hopkins Center for Inherited Disease Research (CIDR) using the Illumina HumanOmni1Quad_v1-0_B BeadChip (Illumina, San Diego, CA, USA). Individuals were excluded if they were unexpected duplicates, gender discrepancy and unexpected relatedness. For this analysis, 5.1\% of cases and $0.6 \%$ of controls that had a history of MI (based on self-report) were removed from analysis.

\section{Milano}

This study includes consecutive Italian patients referred to Besta Institute from 2000 to 2009 with stroke and included in the Besta Cerebrovascular Diseases Registry (CEDIR). Ischemic stroke cases, first ever or recurrent, confirmed on brain imaging, were selected for this study. All cases were of self-reported Caucasian ancestry and had clinically relevant diagnostic workup performed. All cases were phenotyped by an experienced stroke neurologist according to TOAST criteria, based on relevant clinical imaging and available information on cardiovascular risk factors. Controls are Italian individuals enrolled within the PROCARDIS Study, with no personal or sibling history of coronary heart disease before age 66 years.

\section{Stroke in Young Fabry Patients (SIFAP)}

SIFAP study is a multicenter study carried out to determine the frequency of Fabry disease in an unselected group of young patients (18 - 55 years of age) with acute cerebrovascular events (CVE) defined as having had an acute ischemic stroke or transient ischemic attack less than 3 months before enrollment into the study. For this project, about ischemic stroke cases recruited from 15 sites throughout Germany and determined not to have Fabry Disease were included in the analysis. All were of European ancestry and had age of first stroke of 18-55 years. The diagnosis of Fabry disease was based in males as well as in females in the first level on the sequencing data of the entire exon structure including promoter of the $\alpha$-galactosidase gene. In cases where a mutation was detected biochemical analysis was done. Stroke cases from SIFAP were genotyped at CIDR using the Illumina Human Omni 2.5M-Quad array and controls free of cardiovascular diseases were selected from the KORA Study previously genotyped at CIDR in the same platform. The Cooperative Health Research in the Region of Augsburg (KORA) study is a population-based study of cardiovascular and metabolic traits carried out in the region of Augsburg, Southern Germany. Extensive care will be taken in the data cleaning process to minimize artifactual differences in allele frequencies between cases and controls that may have occurred due to cases and controls being genotyped at different times (although on the same platform and in the same laboratory).

\section{Risk Assessment of Cerebrovascular Events (RACE) Study, Pakistan}


RACE is a retrospective case-control study designed to identify and evaluate genetic, lifestyle and biomarker determinants of stroke and its subtype in Pakistan. Samples were recruited from six hospital centers in Pakistan. Cases were eligible for inclusion in the study if they: (1) are aged at least 18 years; (2) presented with a sudden onset of neurological deficit affecting a vascular territory with sustained deficit at 24 hours verified by medical attention within 72 hours after onset (onset is defined by when the patient was last seen normal and not when found with deficit); (3) the diagnosis was supported by CT/MRI; and (4) presented with a Modified Rankin Score of $<2$ prior to the stroke. TOAST and Oxfordshire classification systems were used to sub-phenotype all stroke cases. Control participants were individuals enrolled in the Pakistan Risk of Myocardial Infarction Study (PROMIS), a case-control study of acute MI based in Pakistan. Controls in PROMIS were recruited following procedures and inclusion criteria as adopted for RACE cases. In order to minimize any potential selection biases, PROMIS controls selected for this stroke study were frequency matched to RACE cases based on age and gender and were recruited in the following order of priority: (1) non-blood related or blood related visitors of patients of the out-patient department; (2) non-blood related visitors of stroke patients; (3) patients of the out-patient department presenting with minor complaints.

\section{Wellcome Trust Case-Control Consortium 2 (WTCCC2)}

The WTCCC2 samples were genotyped as part of the WTCCC 2 ischemic stroke study. Stroke cases included samples recruited by investigators at St. George's University London (SGUL) and University of Oxford in the UK and the Department of Neurology, Klinikum Großhadern, Ludwig-MaximiliansUniversity, Munich.

The SGUL collection comprised 1224 ischemic stroke samples from a hospital based setting. All cases were of self-reported Caucasian ancestry. Ischemic stroke subtypes were determined according to TOAST criteria based on relevant clinical imaging and available information on cardiovascular risk factors. The University of Oxford collection comprised 896 ischemic stroke cases, consecutively collected as part of the Oxford vascular study (OXVASC). Cases were of self-reported Caucasian ancestry, and ischemic stroke subtypes were determined according to TOAST criteria based on relevant clinical imaging. The University of Edinburgh collection comprised 727 ischemic stroke cases, consecutively collected as part of the Edinburgh Stroke Study. Cases were of self-reported Caucasian ancestry, with ischemic stroke subtypes determined according to TOAST criteria based on relevant clinical and imaging data.

The Munich samples included 1383 ischemic stroke cases. Cases were consecutive European Caucasians recruited from a single dedicated Stroke Unit at the Department of Neurology, Klinikum Großhadern, Ludwig-Maximilians-University, Munich. Ischemic stroke subtypes were determined according to TOAST criteria based on relevant clinical and imaging data. Controls for the UK samples were drawn from shared WTCCC controls obtained from the 1958 Birth Cohort. This is a prospectively collected cohort of individuals born in 1958 (http://www.b58cgene.sgul.ac.uk/), and ascertained as part of the national child development study (http://www.cls.ioe.ac.uk/studies.asp?section=000100020003). Data from this cohort are available as a common control set for a number of genetic and epidemiological studies. For the German samples controls were Caucasians of German origin participating into the population KORAgen study (www.gsf.de/kora/en/english.html). This survey represents a gender- and age stratified random sample of all German residents of the Augsburg area and consists of individuals 25 to 74 years of age, with about 300 subjects for each 10-year increment. All controls were free of a history of stroke or transient ischemic attack. 


\section{WTCCC Immunochip}

The Immunopchip samples consisted of 5 cohorts of patients of European ancestry with ischemic stroke. Participating centers were based in Belgium, Germany, Poland, Sweden, and the UK (2 cohorts, one from London [Imperial College; the BRAINS study] and one from Glasgow). All cohorts provided geographically and ancestry-matched controls. For the purposes of meta-analysis, the UK cohorts were treated as a single center in line with previous analyses undertaken in WTCCC2. The 5 discovery phase cohorts used the commercially available Immunochip array (Illumina, San Diego, CA), comprising 200,000 SNPs. Genotyping for the 5 case cohorts was performed at the Sanger Centre, Hinxton, Cambridge, UK. Swedish controls were provided and genotyped by the Swedish SLE network, Uppsala, Sweden. Belgian control samples were provided through the efforts of the International Multiple Sclerosis Genetics Consortium. The Immunochip datasets were each imputed separately to the 1,000 Genomes Phase 1 integrated variant set (March 2012) using IMPUTE v2.2.2.

\section{Studies in METASTROKE consortium (excluding studies included in either Stage 1 or Stage 2)}

\section{The Atherosclerosis Risk in Communities Study (ARIC)}

The ARIC study is a prospective population-based study of atherosclerosis and clinical atherosclerotic diseases in 15,792 men and women, including 11,478 non-Hispanic white participants, drawn from 4 U.S. communities (Suburban Minneapolis, Minnesota; Washington County, Maryland; Forsyth County, North Carolina, and Jackson, Mississippi). In the first three communities, the sample reflects the demographic composition of the community. In Jackson, only black residents were enrolled. Ancestry was self-reported during an interview. Over 99\% self-identified as either white or black. Only selfidentified whites were included in the analyses. ${ }^{5}$ Hospitalized strokes that occurred by December 31 , 2007 (median follow-up, 18.7 years) were included in the analyses. During annual telephone contacts, trained interviewers asked each ARIC participant to list all hospitalizations during the past year. Hospital records for any hospitalizations identified were then obtained. Moreover, all local hospitals annually provided lists of stroke discharges (International Classification of Diseases, Ninth Revision, Clinical Modification codes 430 to 438), which were surveyed for ARIC participant discharges. Details

on quality assurance for ascertainment and classification of stroke are described elsewhere. ${ }^{6}$ Briefly, the stroke diagnosis was assigned according to criteria adapted from the National Survey of Stroke. ${ }^{7}$ Strokes secondary to trauma, neoplasm, hematologic abnormality, infection, or vasculitis were excluded, and a focal deficit lasting $<24$ hours was not considered to be a stroke. Out-of-hospital stroke was not ascertained and validated; thus, these potential stroke events are not included. Strokes were classified into hemorrhagic stroke (subarachnoid and intracerebral hemorrhage) and ischemic stroke (thrombotic and embolic brain infarction). A stroke was classified as ischemic when a brain CT or MRI revealed acute infarction and showed no evidence of hemorrhage. All definite ischemic strokes were further classified as lacunar, nonlacunar thrombotic, or cardioembolic on the basis of the recorded neuroimaging results. A stroke was classified as “lacunar” when 2 criteria were met: (1) typical location of the infarct (basal ganglia, brain stem, thalamus, internal capsule, or cerebral white matter); and (2) infarct size of $\leq 2 \mathrm{~cm}$ or unstated size. ${ }^{8}$ Definite or probable "cardioembolic" stroke required either (1) autopsy evidence of an infarcted area in the brain and a source of possible cerebral emboli in a vessel or the presence of an aembolus in the brain or (2) medical record evidence of a possible noncarotid source of embolus such as moderate or greater valvular heart disease, atrial fibrillation, cardiac or arterial procedure (e.g., cardiac catheterization, open heart surgery, cerebral angiography, and carotid endarterectomy), or intracardiac thrombus. Definite or probable ischemic strokes that were not classified 
as lacunar or cardioembolic, including atherothrombotic and unclassified thrombotic strokes, were labeled "nonlacunar." Hemorrhagic strokes identified by ARIC were censored at the time of their occurrence.

\section{Bio-Repository of DNA in Stroke (BRAINS)}

The Bio-Repository of DNA in Stroke (BRAINS) is an international study recruiting highly phenotyped patients with stroke. For the purposes of the current work all patients were Caucasians. Diagnosis of stroke was confirmed using positive imaging (MRI or CT) and ischemic stroke subtypes were assigned using TOAST criteria, based on clinical, imaging and risk factor data. Controls were European-Ancestry, stroke-free participants from the shared WTCCC controls, a prospectively collected cohort of individuals born in 1958 (1958 Birth Cohort). The cohort has been described in detail elsewhere. ${ }^{9}$

\section{Cardiovascular Health Study (CHS)}

The CHS is a population-based cohort study of risk factors for coronary heart disease (CHD) and stroke in adults $\geq 65$ years conducted across four field centers in the United States. 6 The original predominantly white cohort of 5,201 persons (4,964 whites) was recruited in 1989-1990 from a random sample of people on Medicare eligibility lists and an additional 687 African-Americans were enrolled subsequently (1992-93) for a total sample of 5,888. Race was determined by self-identification at interview. In addition to the 5 categories used in the ARIC study, participants were also asked a second question as to whether they considered themselves to be of Hispanic origin. To reduce the possibility of confounding by population structure, these analyses were limited to participants of self-described European-ancestry. The study sample for these analyses includes participants who were free of CVD at baseline, had blood samples drawn at their baseline examination, consented to genetic testing, had DNA available, and had successful genome-wide genotyping assay. Participants were examined annually from enrollment to 1999, and since then continue to be under surveillance for stroke. Since baseline, participants have also been contacted twice a year to identify potential cardiovascular events, including stroke. In addition, all hospitalizations were screened for potential stroke events. For suspected events, information was collected from the participant or next of kin, from medical records, and, if needed, from the participant's physician. When available, CT and/or MRI scans or reports were reviewed centrally. Final adjudication of the occurrence of stroke, stroke types, and subtypes was undertaken by vascular neurologists at a consensus conference using all available information. Strokes were classified as ischemic if there was imaging (CT or MRI within 4 weeks), surgical or autopsy evidence excluding a hemorrhage, or in the absence of such direct evidence (in $<10 \%$ of cases in FHS and Rotterdam, none in CHS) if the preponderance of indirect evidence (e.g. deficit limited to one limb or completely resolved within 72 hours, atrial fibrillation in persons not on anticoagulants) suggested the event was an ischemic rather than a hemorrhagic stroke. A stroke was classified as hemorrhagic if there was imaging, surgical, lumbar puncture or autopsy evidence of hemorrhage, and in the absence of direct evidence to the contrary, when the participant lost consciousness permanently or died within hours after onset of focal signs. The stroke type was defined as unknown if there was insufficient information available to categorize the event as ischemic or hemorrhagic. All ischemic and hemorrhagic strokes and strokes of unknown type were included in the analyses of total stroke with one exception: subarachnoid hemorrhages ( $\mathrm{n}=28$ across all studies) were excluded from these analyses since the heritability, risk factors and pathophysiologic mechanisms underlying subarachnoid hemorrhages are distinctly different from other stroke subtypes. Persons with a subarachnoid hemorrhage were censored at the time of the event. Only known ischemic strokes were included in the analysis of ischemic stroke. In secondary analyses we related those SNPs which reached genome-wide significance in our initial GWAS to the specific ischemic stroke subtype of 
atherothrombotic stroke, also called atherothrombotic brain infarction (ABI). We used the best available definitions of definite and possible ABI in each cohort; both large artery atherosclerotic strokes and small-vessel or lacunar strokes were included in this phenotype, events known to be cardioembolic were excluded. For the analysis of ABI, participants were censored when they developed an alternative type of stroke.

\section{deCODE Genetics}

Cases, irrespective of age, were identified from a registry of individuals diagnosed with ischemic stroke or TIA at Landspitali University Hospital in Reykjavik, the only tertiary referral centre in Iceland, during the years 1993 to 2006. The ischemic stroke or TIA diagnoses were based on standard WHO criteria and imaging evidence (either CT or MRI), and were clinically confirmed by neurologists. Eligible patients who survived the stroke were invited to participate the genetic study, either by attending a recruitment center for deCODE's genetic studies, or they were visited at their home by a study nurse. Control subjects were participants from a large variety of genetic programs at deCODE. Individuals with confirmed stroke (identified by cross-matching with hospital lists), who had participated in genetic studies other than those of cardiovascular diseases (CVD) (but not participated in CVD studies) were excluded as controls.

\section{Heart Protection Study (HPS)}

The Heart Protection Study (HPS) was a large randomized trial involving individuals at increased risk of vascular events. Between 1994-1997 20,536 men and women aged 40-80 years were recruited from 69 collaborating hospitals in the United Kingdom (with ethics committee approval). Participants were eligible for inclusion provided they had non-fasting blood total cholesterol concentrations of at least 135 $\mathrm{mg} / \mathrm{dL}$ (3.5 mmol/L) and either a previous diagnosis of coronary disease, ischemic stroke, other occlusive disease of non-coronary arteries, diabetes mellitus, or (if were men 65 years or older) treated hypertension. None of them was on statin therapy. At the initial screening visit, all participants provided written consent and began a "run-in” phase involving 4 weeks of placebo followed by 4 to 6 weeks of 40 mg simvastatin daily, after which compliant and eligible individuals were randomly allocated $40 \mathrm{mg}$ simvastatin daily or matching placebo for approximately 5 years. Individuals entering HPS with a clinical diagnosis of ischemic stroke were used as cases in the METASTROKE study. Individuals entering HPS with pre-existing diabetes but no history of cerebrovascular disease, coronary heart disease or peripheral vascular disease were used as controls.

\section{The Heart and Vascular Health Study (HVH)}

The setting for this study was Group Health (GH), a large integrated health care system in western Washington State. Data were utilized from an ongoing case-control study of incident myocardial infarction (MI) and stroke cases with a shared common control group. Methods for the study have been described previously ${ }^{10-12}$ and are briefly summarized below. The study was approved by the human subjects committee at $\mathrm{GH}$, and written informed consent was provided by all study participants. All study participants were GH members and aged 30-79 years. MI and stroke cases were identified from hospital discharge diagnosis codes and were validated by medical record review. Controls were a random sample of GH members frequency matched to MI cases on age (within decade), sex, treated hypertension, and calendar year of identification. The index date for controls was a computer-generated random date within the calendar year for which they had been selected. For stroke cases, the index date was the date of admission for the first acute stroke. Participants were excluded if they were recent enrollees at GH, had a history of prior stroke, or if the incident event was a complication of a procedure 
or surgery. Trained medical record abstractors collected eligibility and risk factor information from a review of the GH medical record using only data available prior to the index date and through a telephone interview. Medication use was ascertained using computerized GH pharmacy records. A venous blood sample was collected from all consenting subjects, and DNA was extracted from white blood cells using standard procedures. Diagnostic criteria for ischemic stroke were adopted from the Cardiovascular Health Study ${ }^{13}$ These criteria included (1) rapid onset of neurologic deficit or subarachnoid hemorrhage, (2) deficit persisting for longer than 24 hours unless computed tomography or magnetic resonance imaging show evidence of permanent damage, and (3) no underlying brain trauma, tumor, or infection to cause symptoms.

These analyses were limited to ischemic stroke cases, namely those satisfying 1 or more of the following criteria: (a) Focal deficit, without evidence of blood on CT or MRI, (b) Focal deficit, with mottled appearance in the appropriate location on CT, or (c) surgery or autopsy evidence of infarction. Among ischemic strokes, the subtypes were defined as follows: Lacunar stroke ("SVD”) required either: (a) CT/MRI demonstrates a deep area of infarction (decreased density) less than $2 \mathrm{~cm}$. across, or (b) A normal CT, but the clinical syndrome is typical of a lacunar infarction, that is: a pure motor stroke, a pure sensory stroke, hemiparesis plus ataxia, or dysarthria plus a clumsy hand. Embolic stroke (“CE”) required either (a) a recognized source of emboli such as atrial fibrillation, endocarditis, mitral stenosis, thrombus in heart, recent MI or cardiac surgery, or (b) a mottled appearance consistent with infarction on the CT. Atherosclerotic infarction ("LAA") when there is no apparent source of emboli or evidence of lacunar infarction and there is evidence of large vessel atherosclerosis by carotid ultrasound or angiography.

\section{The Ischemic Stroke Genetics Study (ISGS)/ Siblings With Ischemic Stroke Study (SWISS)}

The Siblings with Ischemic Stroke Study (SWISS) is a multicenter affected sibling pair study enrolling probands with ischemic stroke at 66 US medical centers and 4 Canadian medical centers. ${ }^{14}$ All probands are adult men and women over the age of 18 years diagnosed with ischemic stroke confirmed by a study neurologist on the basis of history, physical examination and CT or MR imaging of the brain. Additionally all probands were required to have at least one living sibling with a history of stroke. Siblings were enrolled using proband-initiated contact or direct contact when permitted by Institutional Review Boards. ${ }^{15}$ Clinical exclusion criteria mirrored that in ISGS. Concordant siblings had their diagnosis of ischemic stroke confirmed by review of medical records by a central vascular neurology committee. Subtype diagnoses were assigned to the index strokes of probands and concordant siblings according to TOAST criteria. ${ }^{16}$ Readily available US controls were utilized, including stroke-free participants from the Baltimore Longitudinal Study of Aging and the National Institute of Neurological Diseases and Stroke neurologically normal control series taken from the Coriell Cell Repositories. All controls had been previously genotyped and described in detail elsewhere.

The Ischemic Stroke Genetic Study (ISGS) is a multicenter study where inpatient cases were recruited from five United States academic medical centers.20 Cases are adult men and women over the age of 18 years diagnosed with first-ever ischemic stroke confirmed by a study neurologist on the basis of history, physical examination and CT or MR imaging of the brain who were enrolled within 30 days of onset of stroke symptoms. Cases exclusion criteria include: a mechanical aortic or mitral valve at the time of the index ischemic stroke, central nervous system vasculitis, bacterial endocarditis, cerebral autosomal dominant arteriopathy with subcortical infarcts and leukoencephalopathy (CADASIL), Fabry disease, homocystinuria, mitochondrial encephalopathy with lactic acidosis and stroke-like episodes (MELAS), or sickle cell anemia. Stroke severity at enrollment was assessed using the NIH Stroke Scale with the diagnostic evaluation including head CT (95\%) or MRI (83\%), electrocardiography (92\%), cervical 
arterial imaging (86\%), and echocardiography (74\%). Medical records from all cases were centrally reviewed by a vascular neurology committee and assigned ischemic stroke subtype diagnoses according to criteria from the Trial of ORG10172 (TOAST), the Oxfordshire Community Stroke Project, and the Baltimore-Washington Young Stroke Study.

\section{Rotterdam}

The Rotterdam Study is a population-based cohort study among inhabitants of a district of Rotterdam (Ommoord), The Netherlands, and aims to examine the determinants of disease and health in the elderly with a focus on neurogeriatric, cardiovascular, bone, and eye disease.21 In 1990-1993, 7,983 persons participated and were re-examined every 3 to 4 years. After enrollment in the Rotterdam Study, participants are continuously monitored for incident stroke through automated linkage of the study database with files from general practitioners. Nursing home physicians' files and files from general practitioners of participants who moved out of the district are scrutinized as well. Additional information is obtained from hospital records. Potential strokes are reviewed by research physicians and verified by an experienced stroke neurologist. Stroke is defined as rapidly developing clinical signs of focal or global disturbance of cerebral function with no apparent cause other than a vascular origin. History of stroke at baseline was assessed during the baseline interview and verified in medical records. Strokes are further classified as cerebral infarction or intracerebral hemorrhage based on neuroimaging reports. If neuroimaging is lacking, a stroke is classified as unspecified. Subarachnoid hemorrhages were excluded. Ischemic strokes are subtyped into large-vessel disease, small vessel disease, or cardio-embolic based on all available clinical and imaging data. If insufficient information is present to reliably subtype into one of three categories, the ischemic stroke is classified as unspecified ischemic stroke. For the current study, too few cases of ischemic stroke subtypes were present to reliably perform statistical analyses. Participants were followed from baseline to stroke, death, last health status update when they were known to be stroke-free, or January 1, 2005, whichever came first. Follow-up was complete up to January 1, 2005, for $99.1 \%$ of potential person-years.

\section{The Sahlgrenska Study of Ischemic Stroke (SAHLSIS)}

SAHLSIS has been described in more detail previously. ${ }^{17}$ In brief, Caucasian patients $(n=1088)$ under 70 years of age who presented with first-ever or recurrent acute ischemic stroke were recruited consecutively at four stroke units in western Sweden. Healthy Caucasian community controls $(n=600)$ matched for age and sex from the same geographic area were randomly selected from participants in a population-based survey or the Swedish Population Register. All patients were examined by a physician trained in stroke medicine, at baseline and at a follow-up three months after inclusion. All patients underwent ECG and neuroimaging with computed tomography (CT) and/or magnetic resonance imaging (MRI). Extracranial carotid and vertebral duplex ultrasound, MR angiography, catheter angiogram, transcranial Doppler ultrasound, transthoracic and/or transesophageal echo-cardiography were performed when clinically indicated. IS was defined as an episode of focal neurological deficits with acute onset and lasting $>24$ hours or until death, with no apparent non-vascular cause, and no signs of primary hemorrhage on brain imaging. All participants provided written informed consent prior to enrolment. For participants who were unable to communicate, consent was obtained from their next-ofkin. This study was approved by the Ethics Committee of the University of Gothenburg.

Whole blood was isolated from all individuals for genotyping. Plasma was additionally isolated from the first 600 patients and controls for protein measurement. Genotyping for 600 controls was performed using the Illumina Human OmniExpress $750 \mathrm{~K}$ array at the Broad Institute at Harvard 
Medical School (Cambridge USA). Genotype data for rs7906302 and rs1338423 were extracted from the above array for all genotyped controls in SAHLSIS. Genotyping was performed blinded to case/control status.

\section{Web Resources}

The URLs for data presented herein are as follows:

The 1000 Genomes Project: http://www.1000genomes.org/

GWAMA software: http://www.well.ox.ac.uk/gwama/

METASOFT software: http://genetics.cs.ucla.edu/meta/ QUANTO software: http://biostats.usc.edu/software.html

Ensemble Variant Effect Predictor tool: http://www.ensembl.org/info/docs/tools/vep/index.html SNP Annotation and Proxy Search (SNAP): http://www.broadinstitute.org/mpg/snap/ The Genotype-Tissue Expression project (GTEx) project: http://www.gtexportal.org/home/ The Wellcome Trust Sanger Institute Genevar (GENe Expression VARiation) tool: http://www.sanger.ac.uk/resources/software/genevar/

LocusZoom software: http://csg.sph.umich.edu/locuszoom/

\section{Accession Numbers}

The dbGaP accession number for GEOS data reported in this paper is phs000292.v1.p1. 


\section{Supplemental Tables}

Supplemental Table I. Study design and characteristics of participating studies in the discovery phase.

\begin{tabular}{|c|c|c|c|c|c|c|c|c|}
\hline & CADISP & GEOS EA & GEOS AA & MILANO & RACE 1 & RACE 2 & SIFAP & $\begin{array}{c}\text { WTCCC- } \\
\text { UK }\end{array}$ \\
\hline Cases & 555 & 448 & 381 & 201 & 1218 & 339 & 981 & 382 \\
\hline \multicolumn{9}{|l|}{ Stroke Subtype* } \\
\hline Cardioembolic (CE) & 211 & 90 & 74 & 37 & 226 & 67 & 170 & 44 \\
\hline Large Artery Atherosclerosis (LA) & 67 & 37 & 23 & 34 & 201 & 56 & 184 & 79 \\
\hline Small Vessel (SV) & 31 & 54 & 77 & 12 & 190 & 42 & 104 & 91 \\
\hline Other known causes & 18 & 29 & 24 & N/A & 15 & 6 & 164 & NA \\
\hline Undetermined causes & 228 & 238 & 183 & 67 & 586 & 168 & 331 & 158 \\
\hline First-ever ischemic stroke (\%) & $\sim 100$ & 100 & 100 & 100 & 100 & 100 & N/A & 100 \\
\hline CT/MRI Brain Imaging (\%) & 100 & 97.80 & 96.3 & 100 & 100 & 100 & N/A & 100 \\
\hline Age, mean (SD) & $43.73(9.9)$ & $41.0(7.0)$ & $275(61.4)$ & $45.0(10.4)$ & $50.1(9.9)$ & $50.2(9.2)$ & $41.7(7.4)$ & $51.9(7.3)$ \\
\hline Male, n (\%) & 339 (61.1) & $41.9(6.8)$ & $207(54.3)$ & $120(60.9)$ & $638(52.4)$ & $272(80.4)$ & $599(61.1)$ & $228(59.7)$ \\
\hline Controls & 9259 & 498 & 352 & 407 & 1158 & 3295 & 1825 & 5175 \\
\hline Age, mean (SD) & N/A & $39.5(6.7)$ & $40.0(6.8)$ & $50.8(8.1)$ & $51.9(7.9)$ & $60.9(13.2)$ & $55.2(11.6)$ & $52(?)$ \\
\hline Male, n (\%) & N/A & $282(56.6)$ & $196(55.7)$ & 357 (87.8) & $613(53.0)$ & $1838(55.8)$ & 899 (49.3) & 2611 (50.5) \\
\hline Control Source & Internal & Internal & Internal & Internal & External & External & $\begin{array}{l}\text { External } \\
\text { (KORA } \\
\text { study) }\end{array}$ & $\begin{array}{c}\text { External } \\
\text { (1958 } \\
\text { British Birth }\end{array}$ \\
\hline
\end{tabular}


cohort and

the UK

Blood

Service control group

\author{
N/A: not available \\ * defined by TOAST criteria
}


Supplemental Table II. Study design and characteristics of participating studies in the validation phase.

\begin{tabular}{|c|c|c|c|c|c|c|c|}
\hline & ASGC & Munich & $\begin{array}{c}\text { WTCCC2- } \\
\text { immunochip- } \\
\text { Belgium }\end{array}$ & $\begin{array}{l}\text { WTCCC2- } \\
\text { immunochip- } \\
\text { Germany }\end{array}$ & $\begin{array}{c}\text { WTCCC2- } \\
\text { immunochip- } \\
\text { Krakow }\end{array}$ & $\begin{array}{c}\text { WTCCC2- } \\
\text { immunochip- } \\
\text { Sweden }\end{array}$ & $\begin{array}{c}\text { WTCCC2- } \\
\text { immunochip- } \\
\text { UK }\end{array}$ \\
\hline Cases & 227 & 275 & 97 & 96 & 93 & 96 & 119 \\
\hline First-ever ischemic stroke (\%) & N/A & $94.2 \%$ & N/A & N/A & N/A & N/A & N/A \\
\hline CT/MRI Brain Imaging (\%) & 97.4 & 100 & 100 & N/A & 100 & N/A & 100 \\
\hline Age (mean \pm SD) & $52.3(8.7)$ & $48.8(8.51)$ & $49.9 \pm 10.19$ & $48.7 \pm 10.07$ & $51.0 \pm 8.54$ & $53.4 \pm 6.49$ & $49.8 \pm 9.9$ \\
\hline Male Participants, n (\%) & $151(66.5)$ & $188(68.4)$ & $67(71.1)$ & $65(67.7)$ & $58(62.3)$ & 69 (71.9) & $73(61.3)$ \\
\hline Controls & 1244 & 797 & 319 & 2344 & 255 & 996 & 1790 \\
\hline Age & $66.3(7.5)$ & 62.7(10.9) & N/A & N/A & N/A & N/A & N/A \\
\hline \% Males & $625(50.2)$ & $410(51.4)$ & 152 (47.6) & $1186(50.3)$ & 94 (36.9) & 269 (27.0) & 741 (41.4) \\
\hline Control Source & Internal & External & Internal & Internal & Internal & Internal & Internal \\
\hline
\end{tabular}


Supplemental Table III. Genotyping and analysis methods used by each participating studies in discovery phase

\begin{tabular}{|c|c|c|c|c|c|c|c|}
\hline & CADISP & GEOS & MILANO & SIFAP $^{1}$ & RACE $1^{1}$ & RACE 2 & WTCCC2-UK \\
\hline Genotyping Platform & $\begin{array}{l}\text { Human610-Quad } \\
\text { BeadChip } \\
\text { (Illumina, San } \\
\text { Diego, USA) }\end{array}$ & $\begin{array}{l}\text { Illumina } \\
\text { HumanOmni1- } \\
\text { Quad_v1-0_B }\end{array}$ & $\begin{array}{l}\text { Cases: Illumina } \\
\text { Human610-Quad } \\
\text { v1_B or } \\
\text { Human660W-Quad } \\
\text { v1_A ; Controls: } \\
\text { Illumina } \\
\text { HumanHap610-Quad }\end{array}$ & $\begin{array}{l}\text { Illumina Human } \\
\text { Omni 2.5M-Quad } \\
\text { array }\end{array}$ & $\begin{array}{l}\text { Illumina } \\
\text { Human660W- } \\
\text { Quad }\end{array}$ & $\begin{array}{l}\text { Illumina } \\
\text { HumanOmni } \\
\text { express }\end{array}$ & $\begin{array}{l}\text { Cases: Illumina } \\
\text { Human660W- } \\
\text { Quad ; Controls: } \\
\text { Illumina } \\
\text { Human1.2M-Duo }\end{array}$ \\
\hline QC filters & $\begin{array}{l}\text { Individuals with a } \\
\text { call rate }<0.95 \text {, sex } \\
\text { mismatch and } \\
\text { duplicates were } \\
\text { excluded. }\end{array}$ & $\begin{array}{l}\text { Individuals with } \\
\text { unexpected } \\
\text { relatedness, } \\
\text { gender mismatch, } \\
\text { population outliers } \\
\text { were excluded; } \\
\text { SNPs with missing } \\
\text { call rate }>=5 \% \text {, } \\
\text { HWE P }<0.0001 \text {, } \\
\text { monomorphic } \\
\text { SNP were } \\
\text { excluded }\end{array}$ & $\begin{array}{l}\text { Exclude individuals } \\
\text { with } \\
\text { unexpected } \\
\text { relatedness, gender } \\
\text { mismatch, population } \\
\text { outliers; } \\
\text { Exclude SNPs } \\
\text { genotyped in }<99 \% \\
\text { of individuals, HWE } \\
\text { p<0.0001 or } \\
\mathrm{MAF}<0.01\end{array}$ & $\begin{array}{l}\text { Exclude SNPs with } \\
\text { missing call rate } \\
>=5 \%, \mathrm{HW} \\
\mathrm{P}<0.0001 \text {, } \\
\text { monomorphic SNP }\end{array}$ & $\begin{array}{l}\text { Exclude SNPs } \\
\text { with missing } \\
\text { call rate }>=5 \% \text {, } \\
\text { HW } \mathrm{P}<0.0001 \text {, } \\
\text { monomorphic } \\
\text { SNP }\end{array}$ & $\begin{array}{l}\text { Exclude SNPs } \\
\text { with missing call } \\
\text { rate }>=5 \% \text {, HW } \\
\mathrm{P}<0.0001 \text {, } \\
\text { monomorphic } \\
\text { SNP }\end{array}$ & $\begin{array}{l}\text { Exclude } \\
\text { Samples as outliers } \\
\text { on call rate, } \\
\text { ancestry, } \\
\text { heterozygosity and } \\
\text { average probe } \\
\text { intensity using a } \\
\text { Bayesian } \\
\text { clustering } \\
\text { algorithm. Samples } \\
\text { were also removed } \\
\text { if they exhibited } \\
\text { gender or cryptic } \\
\text { relatedness with } \\
\text { other WTCCC2 } \\
\text { samples; Exclude } \\
\text { SNPs genotyped in } \\
<99 \% \text { of } \\
\text { individuals, HWE } \\
\text { p<0.0001 or } \\
\text { MAF }<0.01\end{array}$ \\
\hline Pre-phasing software & SHAPE-IT & IMPUTE2 & no prephasing & IMPUTE2 & IMPUTE2 & IMPUTE2 & IMPUTE2 \\
\hline Imputation software & IMPUTE2 & IMPUTE2 & IMPUTE2 & IMPUTE2 & IMPUTE2 & IMPUTE2 & IMPUTE2 \\
\hline $\begin{array}{l}\text { 1KG reference panel } \\
\text { used (website link) }\end{array}$ & $\begin{array}{l}\text { 1000G Phase } 1 \\
\text { integrated variant } \\
\text { set (Mar 2012) }\end{array}$ & $\begin{array}{l}\text { 1000G phase } 1 \\
\text { interim set (June } \\
\text { 2011) }\end{array}$ & $\begin{array}{l}\text { 1000G Phase } 1 \\
\text { integrated variant set } \\
\text { (Mar 2012) }\end{array}$ & $\begin{array}{l}\text { 1000G phase } 1 \\
\text { interim set (June } \\
\text { 2011) }\end{array}$ & $\begin{array}{l}\text { 1000G phase } 1 \\
\text { interim set } \\
\text { (June } 2011 \text { ) }\end{array}$ & $\begin{array}{l}\text { 1000G phase } 1 \\
\text { interim set (June } \\
\text { 2011) }\end{array}$ & $\begin{array}{l}\text { 1000G Phase } 1 \\
\text { integrated variant } \\
\text { set (Mar 2012) }\end{array}$ \\
\hline Model adjustments & sex, PC1-10 & $\begin{array}{l}\text { age, study phase, } \\
\text { PC1 }\end{array}$ & sex, PC1 \& PC5 & Age, sex, PC1-5 & $\begin{array}{l}\text { adjusted for } \\
\text { age, sex, PCs1- }\end{array}$ & $\begin{array}{l}\text { adjusted for age, } \\
\text { sex, PCs1-10 }\end{array}$ & sex \\
\hline
\end{tabular}


${ }^{1}$ For RACE and SIFAP studies where controls were genotyped separately from cases, raw scan data from cases and controls were clustered together to obtain a combined set of genotypes. In addition, a subset of control subjects (28 control subjects for SIFAP and 95 control subjects for RACE) were re-genotyped together with cases to provide cross-set duplicates. This joint clustering was used to minimize possible artifactual differences in allelic frequency between cases and controls due to the fact that they were genotyped at different times and the cross-set duplicates were used to detect such artifacts that may have occurred. 
Supplemental Table IV. Genotyping and analysis methods used in the validation studies.

\begin{tabular}{|c|c|c|c|c|c|c|c|}
\hline & ASGC & Munich & $\begin{array}{c}\text { WTCCC2- } \\
\text { immunochip- } \\
\text { Belgium } \\
\end{array}$ & $\begin{array}{l}\text { WTCCC2- } \\
\text { immunochip- } \\
\text { Germany } \\
\end{array}$ & $\begin{array}{c}\text { WTCCC2- } \\
\text { immunochip- } \\
\text { Krakow } \\
\end{array}$ & $\begin{array}{c}\text { WTCCC2- } \\
\text { immunochip- } \\
\text { Sweden } \\
\end{array}$ & $\begin{array}{c}\text { WTCCC2- } \\
\text { immunochip-UK } \\
\end{array}$ \\
\hline Genotyping Platform & $\begin{array}{l}\text { Human610-Quad } \\
\text { BeadChip } \\
\text { (Illumina, San } \\
\text { Diego, USA) }\end{array}$ & $\begin{array}{l}\text { Human660W- } \\
\text { Quad (cases) / } \\
\text { Human } 550 \\
\text { (controls) }\end{array}$ & $\begin{array}{l}\text { Illumina } \\
\text { Immunochip }\end{array}$ & $\begin{array}{l}\text { Illumina } \\
\text { Immunochip }\end{array}$ & $\begin{array}{l}\text { Illumina } \\
\text { Immunochip }\end{array}$ & $\begin{array}{l}\text { Illumina } \\
\text { Immunochip }\end{array}$ & $\begin{array}{l}\text { Illumina } \\
\text { Immunochip }\end{array}$ \\
\hline QC filters & $\begin{array}{c}\text { Call rate }<97 \% \text {, } \\
\text { MAF }<0.5 \%, \text { P- } \\
\text { HWE }<1 \times 10-4 \text {, } \\
\text { ambiguous SNPs, } \\
\text { SNPs not in } \\
\text { 1000G, SNPs that } \\
\text { couldn't be lifted } \\
\text { to B37 }\end{array}$ & $\begin{array}{l}\text { Bayesian } \\
\text { clustering } \\
\text { approach }\end{array}$ & $\begin{array}{l}\text { Exclude individuals } \\
\text { with high } \\
\text { heterozygosity, high } \\
\text { missingness, } \\
\text { relatedness to other } \\
\text { individuals or if they } \\
\text { did not segregate } \\
\text { with HapMap II } \\
\text { CEU individuals } \\
\text { based on PCA } \\
\text { analysis using } \\
\text { EIGENSTRAT. } \\
\text { Exclude SNPs with } \\
\text { high missingness, } \\
\text { deviation from } \\
\text { HWE, low MAF } \\
(<0.01)\end{array}$ & $\begin{array}{l}\text { Exclude individuals } \\
\text { with high } \\
\text { heterozygosity, } \\
\text { high missingness, } \\
\text { relatedness to other } \\
\text { individuals or if } \\
\text { they did not } \\
\text { segregate with } \\
\text { HapMap II CEU } \\
\text { individuals based } \\
\text { on PCA analysis } \\
\text { using } \\
\text { EIGENSTRAT. } \\
\text { Exclude SNPs with } \\
\text { high missingness, } \\
\text { deviation from } \\
\text { HWE, low MAF } \\
\text { (<0.01) }\end{array}$ & $\begin{array}{l}\text { Exclude individuals } \\
\text { with high } \\
\text { heterozygosity, } \\
\text { high missingness, } \\
\text { relatedness to other } \\
\text { individuals or if } \\
\text { they did not } \\
\text { segregate with } \\
\text { HapMap II CEU } \\
\text { individuals based } \\
\text { on PCA analysis } \\
\text { using } \\
\text { EIGENSTRAT. } \\
\text { Exclude SNPs with } \\
\text { high missingness, } \\
\text { deviation from } \\
\text { HWE, low MAF } \\
\text { (<0.01) }\end{array}$ & $\begin{array}{l}\text { Exclude individuals } \\
\text { with high } \\
\text { heterozygosity, } \\
\text { high missingness, } \\
\text { relatedness to other } \\
\text { individuals or if } \\
\text { they did not } \\
\text { segregate with } \\
\text { HapMap II CEU } \\
\text { individuals based } \\
\text { on PCA analysis } \\
\text { using } \\
\text { EIGENSTRAT. } \\
\text { Exclude SNPs with } \\
\text { high missingness, } \\
\text { deviation from } \\
\text { HWE, low MAF } \\
\text { (<0.01) }\end{array}$ & $\begin{array}{c}\text { Exclude individuals } \\
\text { with high } \\
\text { heterozygosity, } \\
\text { high missingness, } \\
\text { relatedness to other } \\
\text { individuals or if } \\
\text { they did not } \\
\text { segregate with } \\
\text { HapMap II CEU } \\
\text { individuals based } \\
\text { on PCA analysis } \\
\text { using } \\
\text { EIGENSTRAT. } \\
\text { Exclude SNPs with } \\
\text { high missingness, } \\
\text { deviation from } \\
\text { HWE, low MAF } \\
\text { (<0.01) }\end{array}$ \\
\hline Pre-phasing software & Minimac & MACH & IMPUTE2 & IMPUTE2 & IMPUTE2 & IMPUTE2 & IMPUTE2 \\
\hline Imputation software & Mach & MACH & IMPUTE2 & IMPUTE2 & IMPUTE2 & IMPUTE2 & IMPUTE2 \\
\hline $\begin{array}{l}\text { 1KG reference panel } \\
\text { used (website link) }\end{array}$ & Phase 1 (v3) & $\begin{array}{l}\text { 1000G Phase } 1 \\
\text { integrated variant } \\
\text { set }\end{array}$ & $\begin{array}{l}\text { 1000G Phase } 1 \\
\text { integrated variant set } \\
\text { (Mar 2012); }\end{array}$ & $\begin{array}{l}\text { 1000G Phase } 1 \\
\text { integrated variant } \\
\text { set (Mar 2012); }\end{array}$ & $\begin{array}{l}\text { 1000G Phase } 1 \\
\text { integrated variant } \\
\text { set (Mar 2012); }\end{array}$ & $\begin{array}{l}\text { 1000G Phase } 1 \\
\text { integrated variant } \\
\text { set (Mar 2012); }\end{array}$ & $\begin{array}{l}\text { 1000G Phase } 1 \\
\text { integrated variant } \\
\text { set (Mar 2012); }\end{array}$ \\
\hline Model adjustments & $\begin{array}{l}\text { age, sex and the } \\
\text { first } 4 \text { principal } \\
\text { components of } \\
\text { ancestry }\end{array}$ & No covariates & gender, 5 PCs & gender, 10 PCs & gender, 5 PCs & gender, 5 PCs & gender, 10 PCs \\
\hline
\end{tabular}


Supplemental Table V. Study design and characteristics of METASTROKE cohorts.

\begin{tabular}{|c|c|c|c|c|c|}
\hline Cohorts & $\begin{array}{c}\text { Number of } \\
\text { cases }\end{array}$ & $\begin{array}{l}\text { Number of } \\
\text { controls }\end{array}$ & $\begin{array}{l}\text { Number }(\%) \text { of } \\
\text { cases }<60 \text { years }\end{array}$ & Mean Age (yrs) & Study design \\
\hline ARIC & 385 & 8803 & $42(10.9)$ & $57.3 \pm 5.3$ & Population-based, prospective \\
\hline BRAINS & 361 & 444 & $90(24.9)$ & $74.4 \pm 14.2$ & Cross-sectional \\
\hline CHS & 454 & 2817 & $0(0)$ & $81.6 \pm 6.11$ & Population-based, prospective \\
\hline deCODE & 2391 & 26970 & N/A & $73.3 \pm 12.1$ & Cross-sectional \\
\hline HPS & 578 & 468 & $231(40.0)$ & $64.9 \pm 7.5$ & Cross-sectional \\
\hline $\mathrm{HVH}$ & 566 & 1290 & $97(17.1)$ & $69.2 \pm 8.6$ & Cross-sectional \\
\hline ISGS/SWISS & 1070 & 2329 & N/A & $66.5 \pm 13.6$ & Cross-sectional \\
\hline Rotterdam & 367 & 5396 & N/A & $70.8 \pm 7.5$ & Population-based, prospective \\
\hline
\end{tabular}

N/A: information not available 
Supplemental Table VI. SNPs with suggestive associations with early-onset ischemic stroke and their proxy SNPs in chr10 region.

\begin{tabular}{|c|c|c|c|c|c|c|c|c|c|c|}
\hline \multirow[b]{2}{*}{$\mathbf{S N P}^{1}$} & \multirow[b]{2}{*}{$\begin{array}{l}\text { Position } \\
\text { (hg18) }\end{array}$} & \multirow[b]{2}{*}{ variant } & \multirow[b]{2}{*}{$\begin{array}{l}\text { Association p- } \\
\text { value for young- } \\
\text { onset stroke in } \\
\text { the Discovery } \\
\text { Phase }\end{array}$} & \multirow[b]{2}{*}{ AFR_MAF } & \multirow[b]{2}{*}{ ASN_MAF } & \multirow[b]{2}{*}{ EUR_MAF } & \multicolumn{3}{|c|}{$\begin{array}{c}\text { LD with rs11196288 } \\
\text { (r2/D') }\end{array}$} & \multirow[b]{2}{*}{$\begin{array}{l}\text { Functional } \\
\text { Prediction }\end{array}$} \\
\hline & & & & & & & CEU & YRI & CHB/JPT & \\
\hline rs4075717 & 115037998 & G/A & $4.15 \mathrm{E}-05$ & 0.02 & 0.21 & 0.04 & $0.618 / 0.844$ & NA & $0.117 / 0.452$ & \\
\hline rs12219131 & 115038675 & $\mathrm{C} / \mathrm{T}$ & $1.65 \mathrm{E}-05$ & 0.23 & 0.21 & 0.05 & $0.618 / 0.844$ & $0.011 / 0.847$ & $0.117 / 0.452$ & \\
\hline rs11196283 & 115039246 & $\mathrm{C} / \mathrm{T}$ & $1.46 \mathrm{E}-05$ & 0.22 & 0.21 & 0.04 & $0.529 / 0.727$ & $0.002 / 0.125$ & $0.103 / 0.412$ & \\
\hline rs4917648 & 115042323 & A/G & 3.50E-06 & 0.23 & 0.2 & 0.06 & $0.618 / 0.844$ & $0.011 / 1.000$ & $0.196 / 0.600$ & \\
\hline rs11196284 & 115045236 & $\mathrm{C} / \mathrm{T}$ & $1.29 \mathrm{E}-05$ & 0.01 & 0.19 & 0.04 & $0.737 / 1$ & NA & $0.173 / 0.616$ & \\
\hline rs11196287 & 115052431 & $\mathbf{A} / \mathbf{C}$ & 6.25E-07 & 0.04 & 0.38 & 0.04 & $1 / 1$ & $0.330 / 0.574$ & $0.765 / 1.000$ & \\
\hline rs12218673 & 115053330 & $\mathrm{C} / \mathrm{T}$ & $1.36 \mathrm{E}-05$ & 0.02 & 0.34 & 0.04 & $0.737 / 1$ & $0.001 / 1.000$ & $0.960 / 1.000$ & \\
\hline rs61872854 & 115055671 & A/G & 2.85E-07 & 0.05 & 0.35 & 0.04 & $1 / 1$ & NA & $1 / 1$ & \\
\hline rs7906302 & 115056097 & G/T & 1.09E-06 & 0.15 & 0.41 & 0.05 & $0.881 / 1$ & $0.231 / 1.000$ & $0.765 / 1.000$ & \\
\hline rs4918806 & 115057210 & $\mathbf{C} / \mathbf{G}$ & 4.44E-07 & 0.22 & 0.41 & 0.05 & $1 / 1$ & $0.193 / 1.000$ & $0.765 / 1.000$ & Regulatory \\
\hline rs11196288 & 115057443 & A/G & 1.24E-07 & 0.07 & 0.35 & 0.04 & -- & -- & -- & \\
\hline rs11196289 & 115059235 & $\mathrm{C} / \mathrm{T}$ & 5.04E-07 & 0.04 & 0.35 & 0.04 & $0.881 / 1$ & $0.590 / 1.000$ & $0.961 / 1.000$ & \\
\hline rs1338423 & 115060426 & G/A & 6.52E-07 & 0.07 & 0.36 & 0.04 & $0.881 / 1$ & $0.793 / 1.000$ & $0.961 / 1.000$ & Regulatory \\
\hline rs10885429 & 115061139 & $\mathbf{A} / \mathbf{T}$ & $2.74 \mathrm{E}-06$ & 0.14 & 0.42 & 0.06 & $0.881 / 1$ & $0.231 / 1.000$ & $0.737 / 1.000$ & \\
\hline rs4918807 & 115062997 & A/G & 1.22E-06 & 0.07 & 0.36 & 0.04 & $0.881 / 1$ & $1 / 1$ & $0.961 / 1.000$ & \\
\hline rs4918809 & 115063701 & $\mathrm{C} / \mathrm{T}$ & 3.82E-06 & 0.18 & 0.41 & 0.06 & $0.786 / 1$ & $0.217 / 1.000$ & $0.737 / 1.000$ & \\
\hline rs4918810 & 115064197 & $\mathrm{C} / \mathrm{T}$ & 5.17E-07 & 0.07 & 0.35 & 0.04 & $0.881 / 1$ & $1 / 1$ & $1 / 1$ & \\
\hline
\end{tabular}

${ }^{1}$ Twelve SNPs with suggestive associations $\left(\mathrm{P}<5.0 \times 10^{-6}\right.$ in the Discovery Phase, trans-ethnic meta-analysis) are in bold; proxy SNPs (unbold) were identified as having r2>0.8 with any of the 12 stroke-associated SNPs in $\geq 2$ reference populations (CEU, CHB/JPT or YRI) based on 1000 Genomes Pilot data. 
Supplemental Table VII. Top association signals for early-onset ischemic stroke

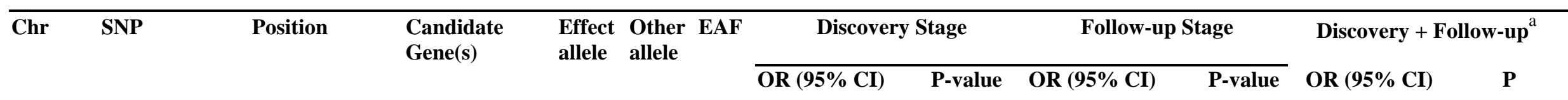

\section{European-only GWA meta-analysis}

\begin{tabular}{|c|c|c|c|c|c|c|c|c|c|c|c|c|}
\hline \multirow{2}{*}{$1 \mathrm{q} 24.2$} & rs1800594 & 169510524 & \multirow{2}{*}{ F5 } & A & G & 0.69 & $1.23(1.13-1.34)$ & $1.39 \mathrm{E}-06$ & $1.08(0.94-1.24)$ & 0.30 & $1.18(1.11-1.27)$ & $2.26 \mathrm{E}-06$ \\
\hline & rs9332599 & 169512980 & & G & A & 0.67 & $1.20(1.11-1.30)$ & 3.90E-06 & $1.05(0.93-1.19)$ & 0.39 & $1.16(1.08-1.23)$ & $1.16 \mathrm{E}-05$ \\
\hline \multirow{2}{*}{$2 \mathrm{p} 15$} & rs74739745 & 61313269 & KIAA1841- & G & A & 0.98 & $1.88(1.49-2.37)$ & 8.52E-08 & $0.77(0.51-1.17)$ & 0.22 & $1.53(1.25-1.87)$ & $2.78 \mathrm{E}-05$ \\
\hline & rs140510319 & 61367943 & LOC39803 & $\mathrm{C}$ & A & 0.97 & $1.75(1.40-2.19)$ & 8.42E-07 & $0.82(0.54-1.25)$ & 0.35 & $1.49(1.23-1.81)$ & 6.13E-05 \\
\hline \multirow{2}{*}{$14 \mathrm{q} 23.3$} & rs12434854 & 65896234 & \multirow{2}{*}{ FUT8 } & G & A & 0.93 & $1.38(1.21-1.58)$ & 2.07E-06 & $1.08(0.87-1.34)$ & 0.50 & $1.29(1.15-1.45)$ & 7.98E-06 \\
\hline & rs12435908 & 66121468 & & A & C & 0.93 & $1.37(1.20-1.56)$ & $3.25 \mathrm{E}-06$ & $1.10(0.89-1.36)$ & 0.39 & $1.29(1.15-1.44)$ & 7.19E-06 \\
\hline \multirow{2}{*}{$17 q 25.3$} & rs6565653 & 78201783 & \multirow{2}{*}{ SLC26A11 } & $\mathrm{T}$ & G & 0.46 & $1.21(1.12-1.31)$ & $1.08 \mathrm{E}-06$ & $1.12(0.87-1.44)$ & 0.39 & $1.20(1.12-1.29)$ & $5.51 \mathrm{E}-07$ \\
\hline & rs12601526 & 78202358 & & $\mathrm{C}$ & $\mathrm{T}$ & 0.50 & $1.21(1.12-1.31)$ & $1.08 \mathrm{E}-06$ & $1.05(0.81-1.36)$ & 0.71 & $1.20(1.11-1.29)$ & $1.14 \mathrm{E}-06$ \\
\hline
\end{tabular}

2. Trans-ethnic GWA meta-analysis

$\begin{array}{rrrcccccccccc} & \text { rs61872854 } & 115055671 & \text { Intergenic } & \text { A } & \text { G } & 0.05 & 1.39(1.22-1.57) & 2.85 \mathrm{E}-07 & 1.80(1.06-3.05) & 0.03 & 1.40(1.25-1.59) & 2.21 \mathrm{E}-08 \\ 10 \mathrm{q} 25.3 & \text { rs11196288 } & 115057443 & \text { (TCF7L2 - } & \text { G } & \text { A } & 0.05 & 1.39(1.23-1.58) & 1.24 \mathrm{E}-07 & 1.80(1.06-3.05) & 0.03 & 1.41(1.25-1.59) & 9.50 \mathrm{E}-09\end{array}$


Supplemental Table VIII. Top associated SNPs in GWAS analysis of stroke subtypes

\begin{tabular}{|c|c|c|c|c|c|c|c|c|c|c|}
\hline \multirow[t]{2}{*}{ Chr } & \multirow[t]{2}{*}{ Position } & \multirow[t]{2}{*}{ SNP } & \multirow[t]{2}{*}{$\begin{array}{l}\text { Candidate } \\
\text { Gene(s) }\end{array}$} & \multirow[t]{2}{*}{ Subtype } & \multirow[t]{2}{*}{$\begin{array}{l}\text { Effect } \\
\text { allele }\end{array}$} & \multirow[t]{2}{*}{$\begin{array}{l}\text { Other } \\
\text { allele }\end{array}$} & \multirow[t]{2}{*}{ EAF } & \multicolumn{3}{|c|}{$\begin{array}{l}\text { Association with stroke } \\
\text { subtype }\end{array}$} \\
\hline & & & & & & & & OR (95\% CI) & P-value & Heterogeneity $\mathrm{I}^{2}$ \\
\hline \multicolumn{11}{|c|}{ 1. European-only } \\
\hline 12 & 21323611 & rs2417957 & SLCO1B1 & LA & $\mathrm{C}$ & $\mathrm{T}$ & 0.97 & $0.36(0.25-0.51)$ & 2.64E-08 & $34 \%$ \\
\hline 10 & 18729855 & rs72786098 & CACNB2 & SV & G & A & 0.97 & $0.28(0.18-0.44)$ & $2.20 \mathrm{E}-08$ & $60 \%$ \\
\hline \multicolumn{11}{|c|}{ 2. Trans-ethnic association } \\
\hline 1 & 51298205 & rs138364069 & FAF1 & LA & $\mathrm{C}$ & $\mathrm{T}$ & 0.98 & $0.28(0.18-0.42)$ & 6.81E-09 & $36 \%$ \\
\hline 1 & 51439456 & rs3176471 & CDKN2C & LA & A & $\mathrm{T}$ & 0.98 & $0.27(0.17-0.43)$ & 4.09E-08 & $57 \%$ \\
\hline
\end{tabular}


Supplemental Table IX. SNPs previously associated with ischemic stroke (and/or ischemic stroke subtypes) and their associations with earlyonset stroke

Association with early-onset ischemic stroke ${ }^{\mathrm{a}}$

\begin{tabular}{|c|c|c|c|c|c|c|c|c|c|c|c|}
\hline \multirow[b]{3}{*}{$\begin{array}{l}\text { Gene } \\
\text { (ref) }\end{array}$} & \multirow[b]{3}{*}{ Chr } & \multirow[b]{3}{*}{ Pos } & \multirow[b]{3}{*}{ SNP (ref) } & \multirow[b]{3}{*}{$\mathbf{R A}$} & \multirow[b]{3}{*}{ RAF } & \multirow[b]{3}{*}{$\begin{array}{l}\text { Previously } \\
\text { reported } \\
\text { OR (trait) }\end{array}$} & \multicolumn{5}{|c|}{ Association with early-onset ischemic stroke ${ }^{\mathrm{a}}$} \\
\hline & & & & & & & \multicolumn{3}{|c|}{ European ancestry $^{b}$} & \multicolumn{2}{|c|}{ Trans-ethnic } \\
\hline & & & & & & & Trait & OR (95\% CI) & $\mathbf{P}$ & OR (95\% CI) & $\mathbf{P}$ \\
\hline \multirow[t]{5}{*}{$N I N J 2^{12,20}$} & 12 & 775199 & rs11833579 & $\mathrm{A}$ & 0.23 & 1.06 (IS) & IS & $1.00(0.91-1.09)$ & 0.96 & $1.0 \quad(0.94-1.07)$ & 0.89 \\
\hline & & & & & & & $\mathrm{CE}$ & $1.00(0.86-1.17)$ & 0.99 & $1.10(0.98-1.24)$ & 0.12 \\
\hline & & & & & & & LAA & $1.05(0.88-1.26)$ & 0.56 & $1.05(0.92-1.20)$ & 0.46 \\
\hline & & & & & & & SV & $1.06(0.87-1.31)$ & 0.55 & $0.96(0.83-1.11)$ & 0.60 \\
\hline & & & & & & & $\mathrm{UE}$ & $0.93(0.82-1.05)$ & 0.23 & $0.99(0.91-1.09)$ & 0.91 \\
\hline \multirow[t]{5}{*}{$A L D H 2^{21}$} & 12 & 112233018 & rs10744777 & $\mathrm{T}$ & 0.68 & 1.10 (IS) & IS & $1.08(1.00-1.17)$ & 0.05 & $1.05(0.97-1.12)$ & $0.21^{\mathrm{d}}$ \\
\hline & & & & & & & $\mathrm{CE}$ & $1.03(0.89-1.19)$ & 0.68 & $1.03(0.92-1.15)$ & 0.64 \\
\hline & & & & & & & LAA & $1.06(0.90-1.25)$ & 0.46 & $1.10(0.97-1.26)$ & 0.13 \\
\hline & & & & & & & SV & $1.06(0.86-1.29)$ & 0.57 & $1.03(0.82-1.30)$ & $0.79^{d}$ \\
\hline & & & & & & & $\mathrm{UE}$ & $1.12(1.00-1.25)$ & 0.05 & $1.06(0.92-1.21)$ & $0.44^{\mathrm{d}}$ \\
\hline \multirow[t]{5}{*}{$\operatorname{PITX}^{12,22}$} & 4 & 111710169 & rs2200733 & $\mathrm{T}$ & 0.12 & 1.36 (CE) & IS & $1.15(1.03-1.28)$ & 0.01 & $1.11(1.02-1.20)$ & 0.02 \\
\hline & & & & & & & $\mathrm{CE}$ & $1.25(1.03-1.52)$ & 0.02 & $1.20(1.03-1.39)$ & 0.02 \\
\hline & & & & & & & LAA & $1.20(0.95-1.53)$ & 0.13 & $1.15(0.84-1.58)$ & $0.37^{\mathrm{d}}$ \\
\hline & & & & & & & SV & $1.29(0.99-1.59)$ & 0.06 & $1.12(0.88-1.43)$ & $0.34^{\mathrm{d}}$ \\
\hline & & & & & & & UE & $1.15(0.98-1.34)$ & 0.06 & $1.14(1.02-1.28)$ & 0.03 \\
\hline
\end{tabular}




\begin{tabular}{|c|c|c|c|c|c|c|c|c|c|c|c|}
\hline \multirow[t]{4}{*}{$Z F H X 3^{12,23}$} & 16 & 73029160 & rs7193343 & $\mathrm{T}$ & 0.23 & 1.25 (CE) & IS & $0.99(0.90-1.09)$ & 0.83 & $1.01(0.94-1.08)$ & 0.84 \\
\hline & & & & & & & LAA & $1.06(0.86-1.31)$ & 0.57 & $1.10(0.95-1.28)$ & 0.19 \\
\hline & & & & & & & SV & $0.91(0.71-1.15)$ & 0.42 & $0.97(0.83-1.13)$ & 0.67 \\
\hline & & & & & & & UE & $1.06(0.92-1.21)$ & 0.42 & $1.04(0.95-1.14)$ & 0.42 \\
\hline & & & & & & & $\mathrm{CE}$ & $1.08(0.94-1.23)$ & 0.29 & $1.06(0.91-1.22)$ & $0.45^{\mathrm{d}}$ \\
\hline & & & & & & & LAA & $1.20(1.03-1.40)$ & 0.02 & $1.15(0.96-1.38)$ & $0.12^{\mathrm{d}}$ \\
\hline & & & & & & & SV & $1.18(0.98-1.41)$ & 0.08 & $1.11(0.94-1.32)$ & $0.20^{\mathrm{d}}$ \\
\hline & & & & & & & UE & $1.05(0.95-1.17)$ & 0.34 & $1.06(0.94-1.20)$ & $0.33^{\mathrm{d}}$ \\
\hline & & & & & & & LAA & $1.23(0.95-1.59)$ & 0.12 & $1.19(0.91-1.54)$ & 0.19 \\
\hline & & & & & & & SV & $1.14(0.85-1.52)$ & 0.38 & $1.05(0.86-1.28)$ & 0.62 \\
\hline & & & & & & & UE & $1.00(0.84-1.19)$ & 0.99 & $1.05(0.92-1.19)$ & 0.47 \\
\hline \multirow[t]{4}{*}{$6 p 21^{5}$} & 6 & 44594159 & rs556621 & A & 0.33 & $1.21(\mathrm{LA})$ & IS & $0.95(0.88-1.03)$ & 0.20 & $0.97(0.91-1.05)$ & $0.54^{\mathrm{d}}$ \\
\hline & & & & & & & $\mathrm{CE}$ & $1.00(0.87-1.15)$ & 0.98 & $1.02(0.86-1.20)$ & $0.82^{\mathrm{d}}$ \\
\hline & & & & & & & LAA & $0.92(0.78-1.09)$ & 0.32 & $0.95(0.83-1.08)$ & 0.41 \\
\hline & & & & & & & SV & $1.00(0.83-1.21)$ & 0.97 & $1.02(0.89-1.17)$ & 0.80 \\
\hline
\end{tabular}


Abbreviations: Chr=chromosome, pos=position, RA=risk allele, RAF=risk allele frequency, IS=ischemic stroke, $\mathrm{CE}=\mathrm{cardioembolic}$ stroke, LAA=large artery atherosclerotic stroke, SV=small vessel stroke, UE=undetermined etiology stroke

${ }^{\text {a }}$ All association results were obtained by meta-analyzing study-specific estimates. In trans-ethnic meta-analysis, odds ratios and p-values taken from the random effects model if evidence for between-study heterogeneity (i.e., $\mathrm{I}^{2}>20 \%$ ); otherwise, odds ratios and p-values based on fixed effect model.

${ }^{\mathrm{b}}$ A total of 2,567 total ischemic stroke cases, including 546 CE, 403 LAA, 294 SV and 1035 UE subtype cases.

${ }^{\mathrm{c}}$ A total of 4,501 total ischemic stroke cases, including $882 \mathrm{CE}, 657$ LAA, 591 SV and 1854 UE subtype cases.

${ }^{\mathrm{d}}$ SNPs with evidence for between-study heterogeneity 


\section{Supplemental Figures}

Supplemental Figure I. QQ plot of (A) European-only meta-analysis and (B) trans-ethnic meta-analysis.

(A)

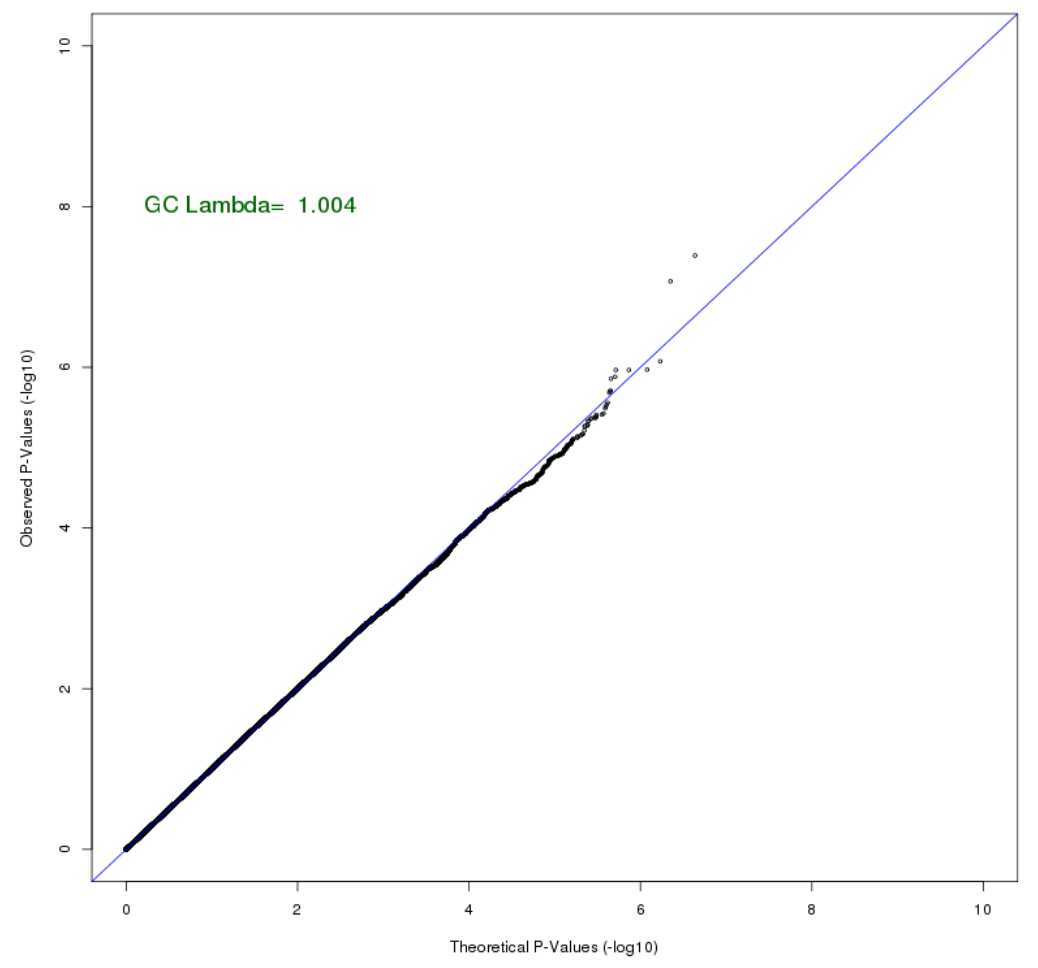

(B)

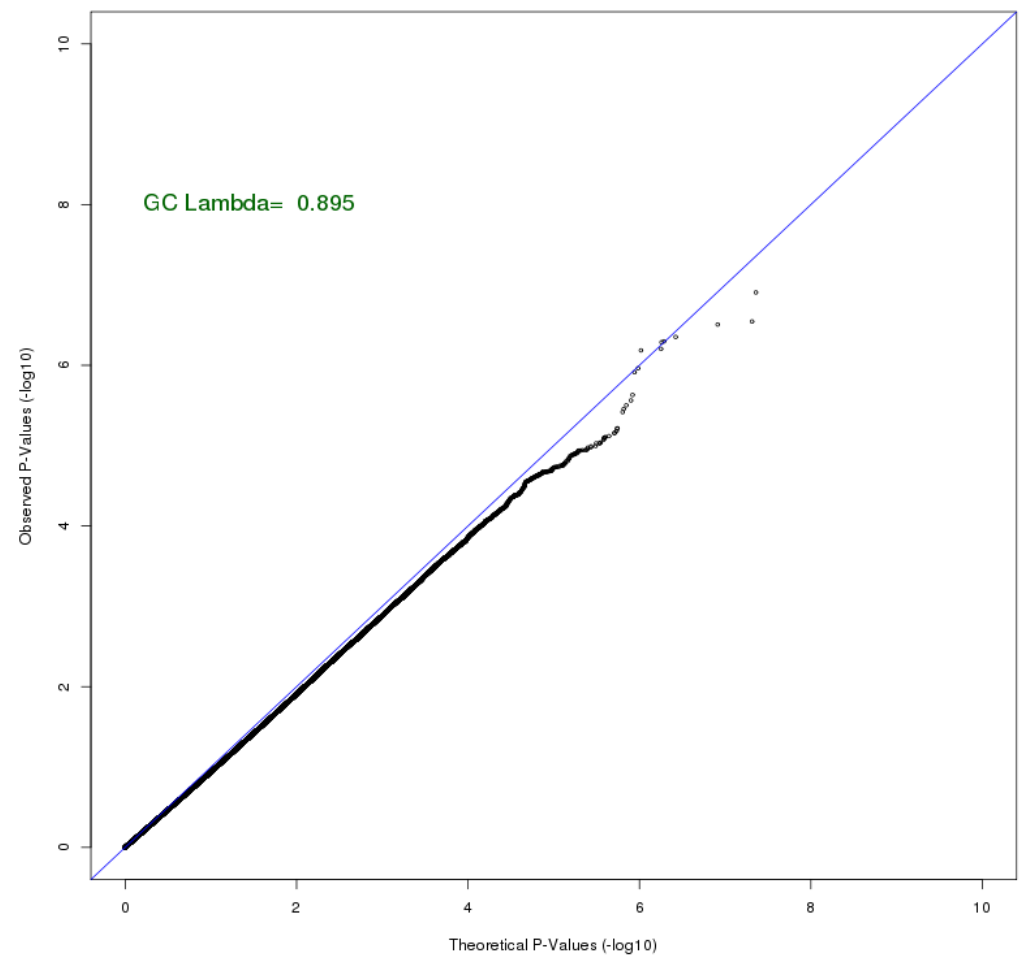


Supplemental Figure II. European-ancestry GWAS results of stroke subtypes (A) cardioembolic, (B) large artery atherosclerotic, (C) small vessel stroke and (D) undetermined.

(A)

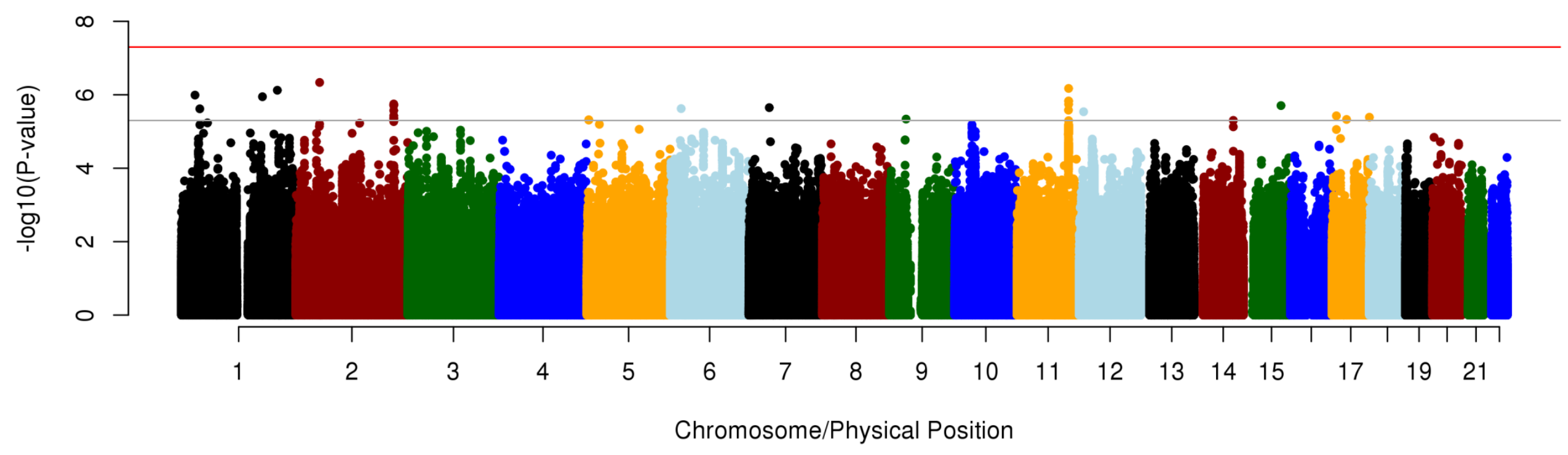

(B) 


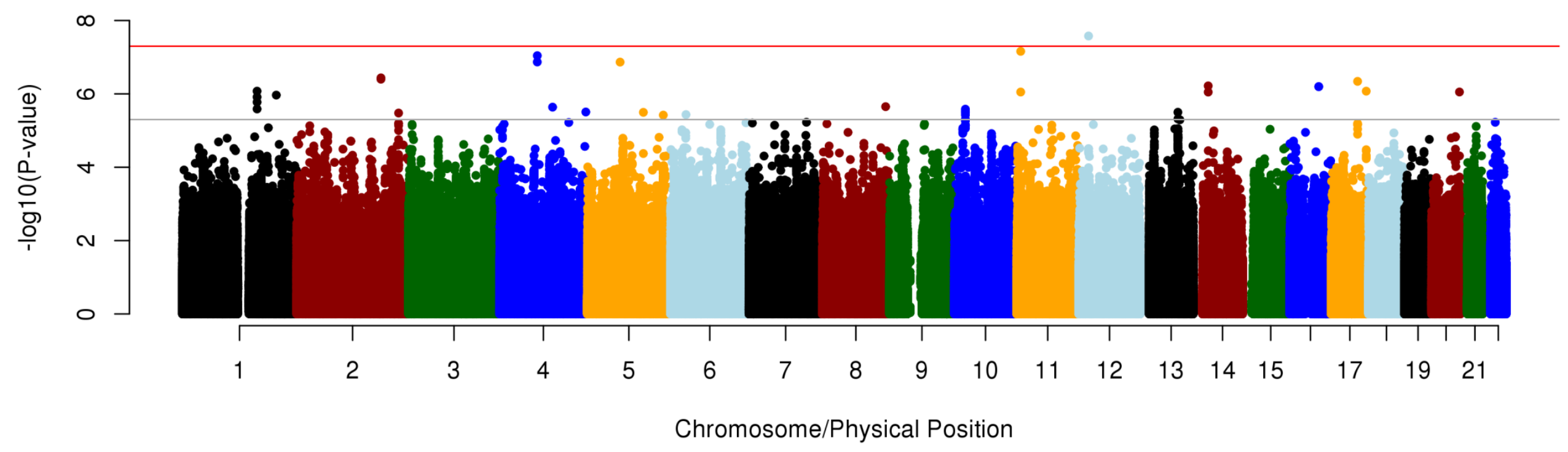

Supplemental Figure II. (continue)

(C)

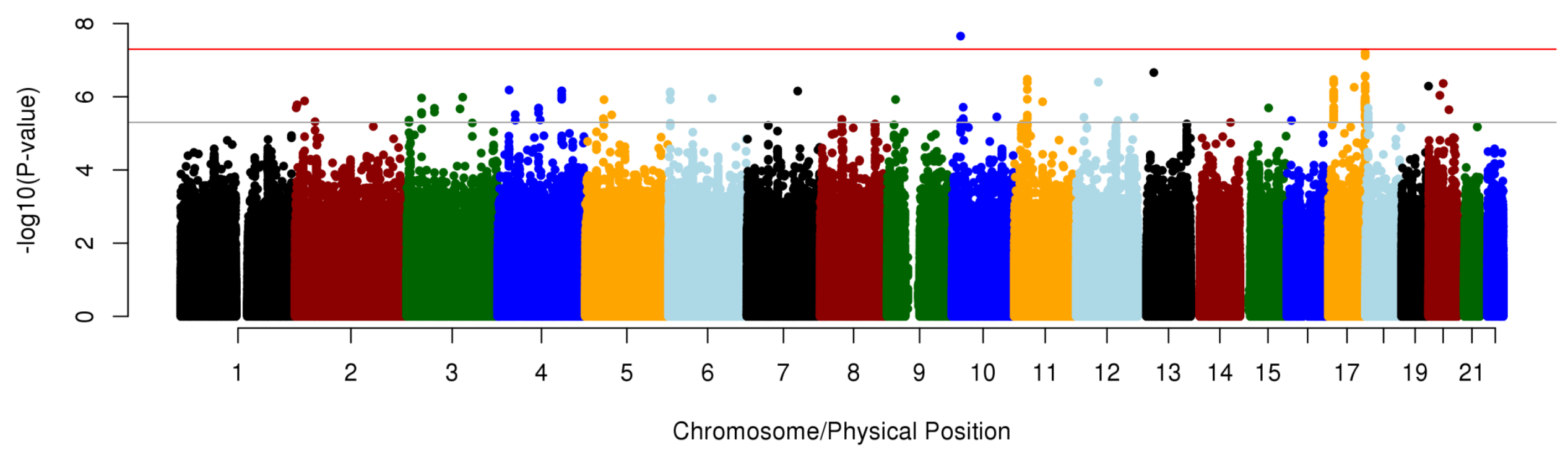


(D)

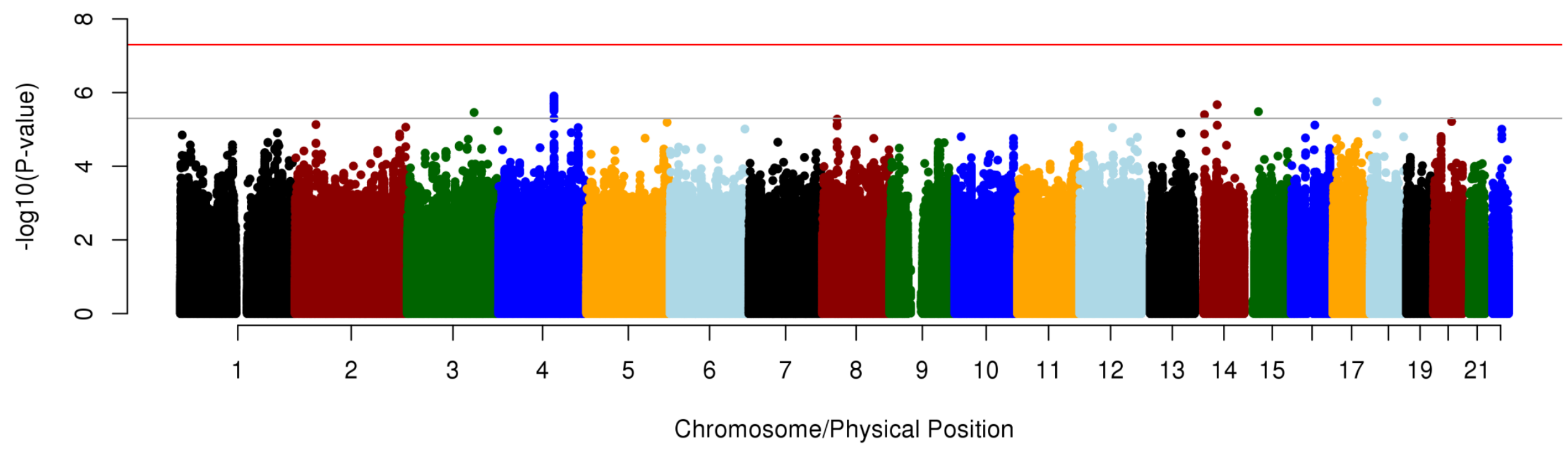


Supplemental Figure III Trans-ethnic GWAS results of stroke subtypes (A) cardioembolic, (B) large artery atherosclerotic, (C) small vessel stroke and (D) undetermined.

(A)

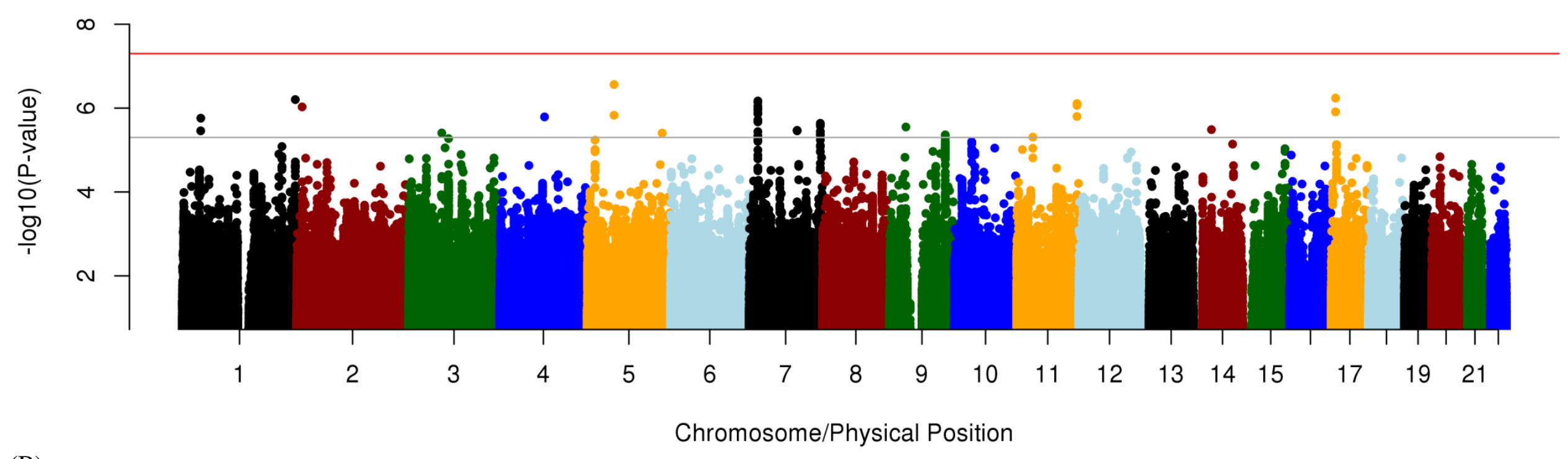

(B) 


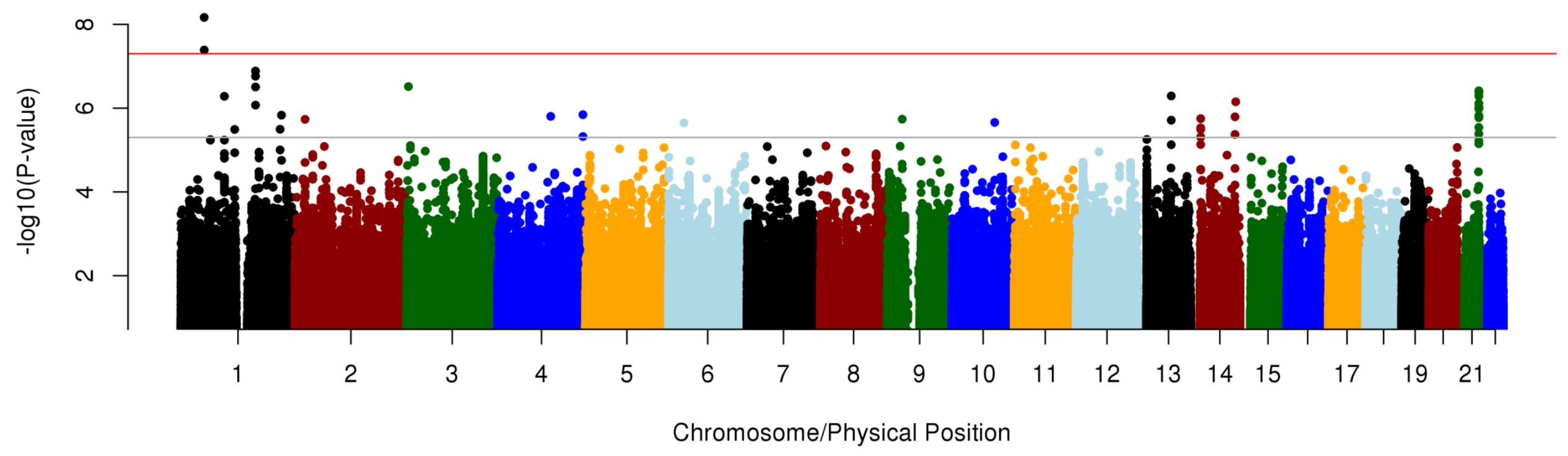


Supplemental Figure III. (continued)

(C)

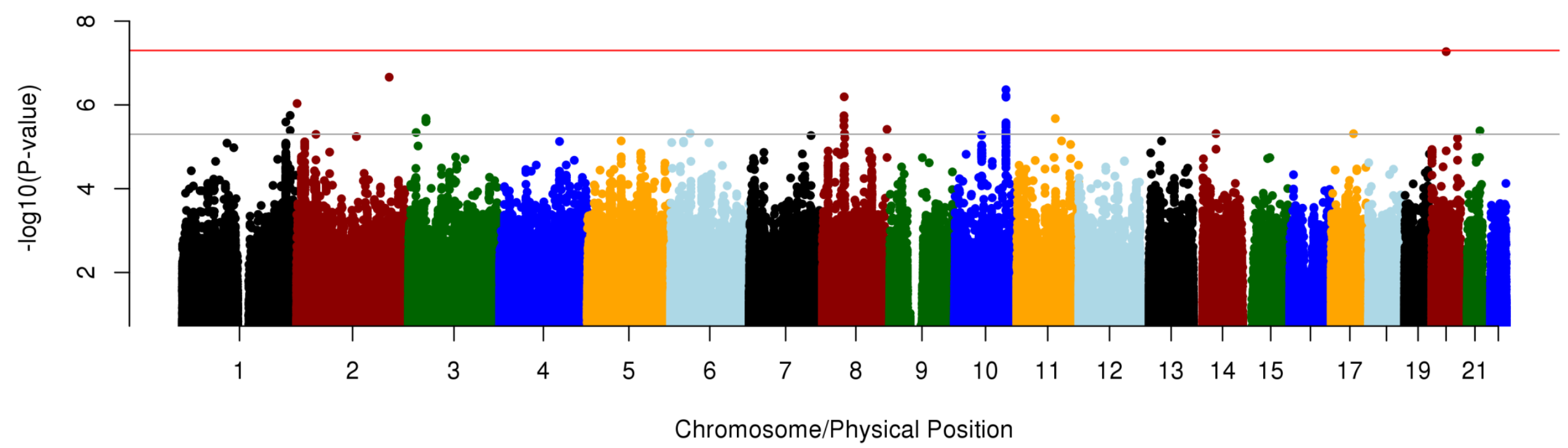

(D) 


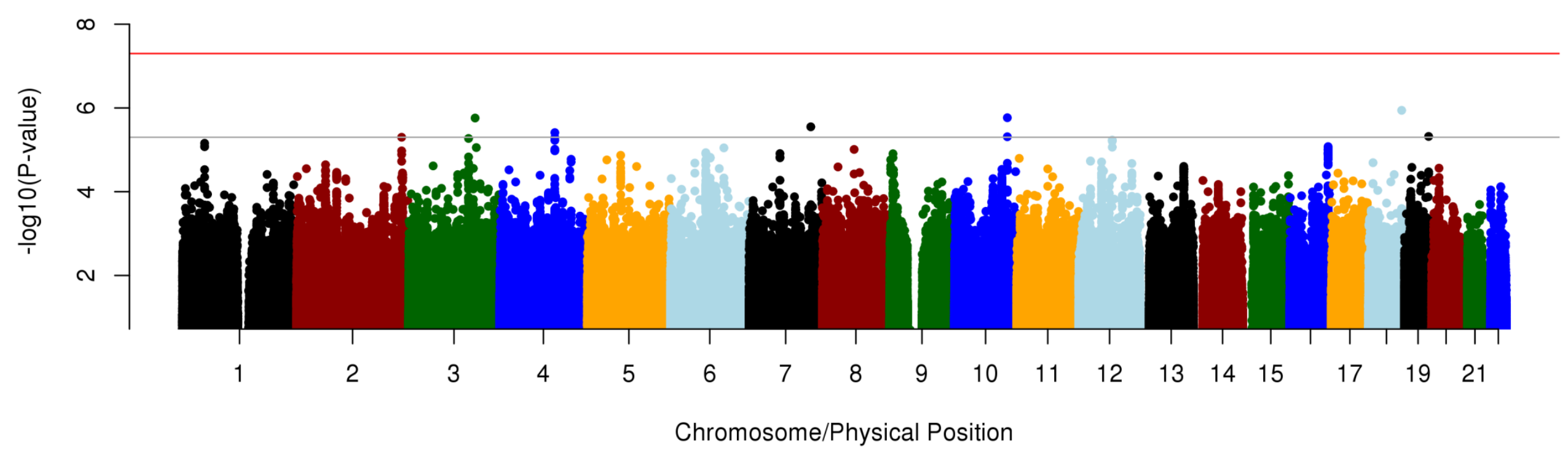




\section{Supplemental References}

1. Adams Jr HP, Bendixen BH, Kappelle LJ, Biller J, Love BB, Gordon DL, et al. Classification of subtype of acute ischemic stroke. Definitions for use in a multicenter clinical trial. TOAST. Trial of Org 10172 in Acute Stroke Treatment. Stroke. 1993;24:35-41

2. Ay H, Benner T, Arsava EM, Furie KL, Singhal AB, Jensen MB, et al. A computerized algorithm for etiologic classification of ischemic stroke: the Causative Classification of Stroke System. Stroke. 2007:38:2979-2984

3. MacClellan LR, Mitchell BD, Cole JW, Wozniak MA, Stern BJ, Gile WH, et al. Familial aggregation of ischemic stroke in young women: the Stroke Prevention in Young Women Study. Genet Epidemiol. 2006;30:602-608

4. Kittner SJ, Stern BJ, Wozniak M., Buchholz DW, Earley CJ, Feeser BR, et al. Cerebral infarction in young adults: the Baltimore-Washington Cooperative Young Stroke Study. Neurology. 1998;50: 890-894

5. The ARIC Investigators. The Atherosclerosis Risk in Communities (ARIC) Study: design and objectives. The ARIC investigators. Am J Epidemiol. 1989;129:687-702

6. Rosamond,WD, Folsom AR, Chambless LE, Wang CH, McGovern PG, Howard G, et al. Stroke incidence and survival among middle-aged adults: 9-year follow-up of the Atherosclerosis Risk in Communities (ARIC) cohort. Stroke. 1999:30:736-743

7. The National Survey of Stroke. National Institute of Neurological and Communicative Disorders and Stroke. Stroke. 1981;2 Pt 2 Suppl 1:I1-91

8. Ay H, Furie KL, Singhal A, Smith WS, Sorensen AG, Koroshetz WJ. (2005). An evidencebased causative classification system for acute ischemic stroke. Annals Neurol. 2005;58: 688-697

9. Yadav S, Schanz R, Maheshwari A, Khan MS, Slark J, de Silva R, et al. Bio-Repository of DNA in stroke (BRAINS): a study protocol. BMC Med Genet. 2011;12:34

10. Psaty BM, Heckbert SR, Atkins D, Lemaitre R, Koepsell TD, Wahl PW, et al. The risk of myocardial infarction associated with the combined use of estrogens and progestins in postmenopausal women. Arch Intern Med. 1994;154:1333-1339

11. Psaty BM, Heckbert SR, Koepsell TD, Siscovick DS, Raghunathan TE, Weiss NS, et al. The risk of myocardial infarction associated with antihypertensive drug therapies. JAMA. 1995:274:620-625

12. Klungel OH, Heckbert SR, Longstreth WT, Jr, Furberg CD, Kaplan RC, Smith NL, et al. Antihypertensive drug therapies and the risk of ischemic stroke. Arch Intern Med. 2001;161:37-43

13. Price TR, Psaty B, O'Leary D, Burke G, Gardin J. Assessment of cerebrovascular disease in the Cardiovascular Health Study. Ann Epidemiol. 1993;3:504-507

14. Meschia JF, Kissela BM, Brott TG, Brown RD Jr., Worrall BB, Beck J, Skarp AN The Siblings With Ischemic Stroke Study (SWISS): a progress report. Clin Med \& Res. 2006;4:12-21 
15. Chen DT, Worrall BB, Brown RD, Jr., Brott TG, Kissela BM, Olson TS, et al. The impact of privacy protections on recruitment in a multicenter stroke genetics study. Neurology. 2005;64:721-724

16. Meschia JF, Barrett KM, Chukwudelunzu F, Brown WM, Case LD, Kissela BM, et al. Interobserver agreement in the trial of org 10172 in acute stroke treatment classification of stroke based on retrospective medical record review. J Stroke Cerebrovasc Dis. 2006;15:266-272

17. Jood K, Ladenvall C, Rosengren A, Blomstrand C, Jern C. Family history in ischemic stroke before 70 years of age: the Sahlgrenska Academy Study on Ischemic Stroke. Stroke. 2005;36:1383-1387 
Permissions: Requests for permissions to reproduce figures, tables, or portions of articles originally published in Stroke can be obtained via RightsLink, a service of the Copyright Clearance Center, not the Editorial Office. Once the online version of the published article for which permission is being requested is located, click Request Permissions in the middle column of the Web page under Services. Further information about this process is available in the Permissions and Rights Question and Answer document.

Reprints: Information about reprints can be found online at: http://www.lww.com/reprints

Subscriptions: Information about subscribing to Stroke is online at: http://stroke.ahajournals.org//subscriptions/ 


\section{Stroke}

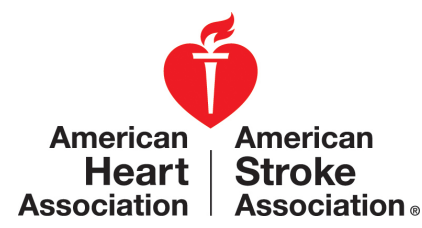

\section{Genome-Wide Association Analysis of Young Onset Stroke Identifies a Locus on Chromosome 10q25 Near HABP2}

Yu-Ching Cheng, Tara M. Stanne, Anne-Katrin Giese, Weang Kee Ho, Matthew Traylor, Philippe Amouyel, Elizabeth G. Holliday, Rainer Malik, Huichun Xu, Steven J. Kittner, John W. Cole, Jeffrey R. O'Connell, John Danesh, Asif Rasheed, Wei Zhao, Stefan Engelter, Caspar Grond-Ginsbach, Yoichiro Kamatani, Mark Lathrop, Didier Leys, Vincent Thijs, Tiina M. Metso, Turgut Tatlisumak, Alessandro Pezzini, Eugenio A. Parati, Bo Norrving, Steve Bevan, Peter M. Rothwell, Cathie Sudlow, Agnieszka Slowik, Arne Lindgren, Matthew R. Walters, Jim Jannes, Jess Shen, David Crosslin, Kimberly Doheny, Cathy C. Laurie, Sandip M. Kanse, Joshua C. Bis, Myriam Fornage, Thomas H. Mosley, Jemma C. Hopewell, Konstantin Strauch, Martina Müller-Nurasyid, Christian Gieger, Melanie Waldenberger, Annette Peters, Christine Meisinger, M. Arfan Ikram, W.T. Longstreth Jr, James F. Meschia, Sudha Seshadri, Pankaj

Sharma, Bradford Worrall, Christina Jern, Christopher Levi, Martin Dichgans, Giorgio B. Boncoraglio, Hugh S. Markus, Stephanie Debette, Arndt Rolfs, Danish Saleheen and Braxton D. Mitchell

Stroke. published online January 5, 2016;

Stroke is published by the American Heart Association, 7272 Greenville Avenue, Dallas, TX 75231 Copyright () 2016 American Heart Association, Inc. All rights reserved.

Print ISSN: 0039-2499. Online ISSN: 1524-4628

The online version of this article, along with updated information and services, is located on the World Wide Web at: http://stroke.ahajournals.org/content/early/2016/01/05/STROKEAHA.115.011328

\footnotetext{
Permissions: Requests for permissions to reproduce figures, tables, or portions of articles originally published in Stroke can be obtained via RightsLink, a service of the Copyright Clearance Center, not the Editorial Office. Once the online version of the published article for which permission is being requested is located, click Request Permissions in the middle column of the Web page under Services. Further information about this process is available in the Permissions and Rights Question and Answer document.
}

Reprints: Information about reprints can be found online at: http://www.lww.com/reprints

Subscriptions: Information about subscribing to Stroke is online at: http://stroke.ahajournals.org//subscriptions/ 